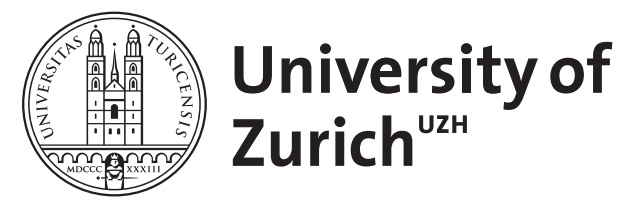

\title{
Birth order and health of newborns
}

\author{
Brenøe, Anne Ardila ; Molitor, Ramona
}

\begin{abstract}
We examine birth order differences in health of newborns and follow the children throughout childhood using high-quality administrative data on individuals born in Denmark between 1981 and 2010. Family fixed effects models show a positive and robust effect of birth order on health at birth; firstborn children are less healthy at birth. During earlier pregnancies, women are more likely to smoke, receive more prenatal care, and are more likely to suffer a medical pregnancy complication, suggesting worse maternal health. We further show that the health disadvantage of firstborns persists in the first years of life, disappears by age seven, and becomes a health advantage in adolescence. In contrast, later-born children are throughout childhood more likely to suffer an injury. The results on health in adolescence are consistent with previous evidence of a firstborn advantage in education and with the hypothesis that postnatal investments differ between first- and later-born children.
\end{abstract}

DOI: https://doi.org/10.1007/s00148-017-0660-1

Posted at the Zurich Open Repository and Archive, University of Zurich

ZORA URL: https://doi.org/10.5167/uzh-160999

Journal Article

Accepted Version

Originally published at:

Brenøe, Anne Ardila; Molitor, Ramona (2018). Birth order and health of newborns. Journal of Population Economics, 31(2):363-395.

DOI: https://doi.org/10.1007/s00148-017-0660-1 


\title{
Birth Order and Health of Newborns: What Can We Learn from Danish Registry Data? June 2017
}

\begin{abstract}
We examine birth order differences in health of newborns and follow the children throughout childhood using high-quality administrative data on individuals born in Denmark between 1981 and 2010. Family fixed effects models show a positive and robust effect of birth order on health at birth; firstborn children are less healthy at birth. During earlier pregnancies, women are more likely to smoke, receive more prenatal care, and are more likely to suffer a medical pregnancy complication, suggesting worse maternal health. We further show that the health disadvantage of firstborns persists in the first years of life, disappears by age seven, and becomes a health advantage in adolescence. In contrast, later-born children are throughout childhood more likely to suffer an injury. The results on health in adolescence are consistent with previous evidence of a firstborn advantage in education and with the hypothesis that postnatal investments differ between first- and later-born children.
\end{abstract}

JEL classification: I10, I12, I14, J12, J13

Keywords: Birth order, child health, fetal health, health at birth, prenatal investments

\author{
Anne Ardila Brenøe \\ Department of Economics, \\ University of Copenhagen \\ Øster Farimagsgade 5 \\ Denmark - 1353 Copenhagen \\ aab@econ.ku.dk; +45 40971695 \\ ORCID: 0000-0002-8045-8032
}

\author{
Ramona Molitor \\ Department of Business Administration \\ and Economics, University of Passau \\ Innstraße 27 \\ Germany - 94032 Passau \\ ramona.molitor@uni-passau.de \\ ORCHID: 0000-0001-8625-7162
}

We are thankful for helpful comments and suggestions from three anonymous referees, Stefan Bauernschuster, Sanni Nørgaard Breining, Michael Grimm, Timo Hener, Edward Samuel Jones, Jacob Alexander Lykke, Torben Heien Nielsen, Helmut Rainer, Heather Royer, members of the University of California Santa Barbara Human Capital Working Group, and participants at the Annual Meeting of the Society of Labor Economists 2016, the Royal Economic Society Conference 2016, the BGPE Research Workshop 2016, the Essen Health Conference 2015, the Bavarian Micro Day 2015, seminars at University of California, Santa Barbara; the University of Copenhagen; the Danish National Centre for Social Research; and the University of Passau. 


\section{Introduction}

Firstborn children perform on average better in cognitive tests, have higher IQ, and attain more schooling than later-born siblings. This is a well-established fact in the economics literature. To explain the negative effect of birth order on education, the empirical literature has mainly focused on postnatal parental investments. ${ }^{1}$ While Pavan (2017) shows that differences in postnatal parental investments across siblings can explain more than one-half of the birth order gap in cognitive test scores, a large part of the gap remains unexplained. Some researchers have hypothesized that birth order differences in educational outcomes might additionally stem from better health of firstborns at birth. ${ }^{2}$ Yet, the existing evidence on the relationship between birth order, health at birth, and prenatal investments is ambiguous (Buckles and Kolka, 2014; Black et al., 2016b; Lehmann et al., 2017). Knowing more about potential birth order differences in health at birth and during childhood provides an important link to the existing literature.

This study examines birth order differences in health at birth and how potential health differences between first- and later-born children evolve throughout childhood. We use Danish administrative data covering over one million child births over a period of three decades. An important feature of this large dataset is that we are able to link each child to its biological siblings, which enables us to compare siblings of different birth order within the same family. Controlling for unobserved heterogeneity between families, we examine a wide range of health outcomes at birth and investigate whether differences in maternal behavior and maternal health during pregnancy can help explain the birth order effects in health at birth. Moreover, we show how birth order differences in health evolve throughout childhood - from age 1 through age 16 - distinguishing between general health conditions and injuries.

Our results are three-fold. First, we challenge traditional predictions in the economics literature and show that firstborn children have a health disadvantage at birth that is robust to a wide range of health measures at birth and apparent in different subpopulations. Second, we analyze different measures of maternal behavior and health outcomes during pregnancy to understand the positive effects of birth order on health at birth. During earlier pregnancies, women are more likely to smoke, visit more often their midwife and special practitioner, and have higher rates of hospitalizations for medical pregnancy complications. A higher demand for pre-

\footnotetext{
${ }^{1}$ See for instance Price (2008), Hotz and Pantano (2015), Lehmann et al. (2017), and Pavan (2017).

${ }^{2}$ See for instance Behrman and Taubman (1986), Ejrnæs and Pörtner (2004), and Hotz and Pantano (2015).
} 
natal care in earlier pregnancies might be indicative of mothers being more worried. However, as we also observe more severe pregnancy complications, we interpret the higher demand for prenatal care as a symptom of worse maternal health in the first compared to subsequent pregnancies. The changes in maternal behavior (smoking) might partly contribute to the overall improvement in maternal health during later pregnancies compared to the first but cannot possibly explain the large health advantage of later-born children. Meanwhile, an improvement in maternal health with higher order pregnancies is consistent with a biological mechanism that improves maternal health with consecutive pregnancies.

Third, the firstborn health disadvantage - measured through hospitalizations for general health conditions - persists during early childhood. Yet, from age seven, this disadvantage disappears and the results indicate a firstborn health advantage in adolescence. At the same time, we observe that later-born children are more likely to suffer an injury throughout childhood. Injuries might not capture a general health condition but may be indicative of differences in children's behavior, parental supervision, or older siblings' influence.

Our results on a health advantage of firstborns in adolescence are consistent with previous studies' findings that firstborns perform better on educational outcomes in adolescence. ${ }^{3}$ However, while the health disadvantage of firstborns in early life disappears in adolescence, Black et al. (2016b) show that, around age 40, firstborns are less healthy than later-borns. The medical literature finds that adverse health conditions at birth become apparent again later in life (Barker et al., 1993a,b; Barker, 1995). Thus, a reappearance of the firstborn health disadvantage is consistent both with our findings and those in Black et al. (2016b). Moreover, our results on general health conditions do not stand in contrast to a higher risk of injury for later-borns. The latter namely supports the hypothesis that postnatal investments favor firstborns, while the health disadvantage of firstborns at birth might be the result of a biological mechanism that improves maternal health with consecutive pregnancies.

The rest of the paper is organized as follows: Section 2 reviews the relevant literature. Section 3 introduces the data and section 4 describes our empirical strategy. Section 5 presents our results on birth order effects in child health at birth and studies potential mechanisms of these birth order differences. Finally, Section 6 examines the evolution of birth order differences in health during childhood. Section 7 concludes.

\footnotetext{
${ }^{3}$ In line with this literature, we observe a negative effect of birth order on ninth grade GPA, see Appendix Table A1.
} 


\section{Previous Literature}

Existing research finds a strong negative correlation between birth order and cognitive test scores (Hotz and Pantano, 2015; Lehmann et al., 2017; Pavan, 2017), schooling outcomes (Behrman and Taubman, 1986; Plug and Vijverberg, 2003; Kantarevic and Mechoulan, 2006), and IQ (Kristensen and Bjerkedal, 2007; Sulloway, 2007; Black et al., 2011). Broadly, to explain these negative effects of birth order on educational outcomes, previous studies have discussed differences in postnatal investments and differences in health at birth across siblings.

A range of studies demonstrate that postnatal parental investments differ across birth orders. Lehmann et al. (2017) show that higher birth order children receive less cognitive support in early life. In support of this finding, Price (2008) documents that, at age four to thirteen, parents spend less quality time with later-born children than with firstborns at the same age. Likewise, Hotz and Pantano (2015) find that parents are less stringent with later-born children with respect to the intensity of monitoring homework and the existence of TV watching rules. Using structural models, Pavan (2017) shows that differences in parental behavior across siblings can explain more than one-half of the birth order gap in cognitive test scores, yet a large part of the gap remains unexplained.

In addition to the role of postnatal investments, previous research has suggested that the effect of birth order on education is already present at birth, but the economics and medical literature come to different conclusions. Theoretically, the economics literature has argued that higher birth order children should show worse health at birth (among others Behrman and Taubman, 1986; Behrman, 1988; Ejrnæs and Pörtner, 2004; Hotz and Pantano, 2015). The underlying argument is the natural correlation between birth order and maternal age, the latter has long been assumed to be negatively associated with health at birth. Tests of this relationship are found mainly in the empirical medical literature which shows, opposite to the predictions of the economic studies, a positive relationship between birth order and health at birth. ${ }^{4}$ Good health at birth is an indicator for better later-life outcomes and, therefore, the results from the medical literature stand in contrast to the negative effect of birth order on education at older ages (among others Behrman and Rosenzweig, 2004; Cunha and Heckman, 2007; Figlio et al., 2014). However, medical studies mostly do not account for socio-economic factors or between family heterogeneity. Not accounting for unobserved family heterogeneity in our study severely underestimates birth order differences in health at birth.

\footnotetext{
${ }^{4}$ For references to the medical literature, see Camilleri and Cremona (1970), Magnus and Bjerkedal (1985), Swamy et al. (2012), and Hinkle et al. (2014).
} 
The empirical economic evidence on the relationship between birth order and health at birth has been elusive. Lehmann et al. (2017) estimate a family fixed effects model of the effect of birth order on health at birth for children in the NLSY79. Consistent with our findings, the authors find a positive but imprecisely estimated effect of birth order on health at birth. In terms of changes in the prenatal environment that could give rise to birth order differences at birth, Buckles and Kolka (2014) show, also using data from the NLSY79, that in higher order pregnancies, women have a lower probability to take prenatal vitamins and to receive prenatal care in the first trimester. Importantly, Buckles and Kolka (2014) argue that this behavioral pattern in prenatal checkups could result from a potentially efficient response to experiences in previous pregnancies. This raises the question whether the need of prenatal care in later pregnancies is lower, which could be because of improvements in maternal health and/or because of greater confidence from experiences in previous pregnancies.

Consequently, we improve upon these previous findings by using a large administrative dataset, allowing us to precisely estimate the effect of birth order on various measures of child health at birth and across different demographic groups. Moreover, our data enables an analysis of maternal health in addition to prenatal behavior. Finally, by documenting how health differences between siblings evolve throughout childhood, we complement the study by Black et al. (2016b), who find that even though later-born children are mostly healthier in adulthood than their firstborn siblings, later-borns behave more risky and report worse health in adulthood.

\section{Data}

Our primary data source is the medical birth register that covers birth information for all children born in Denmark between 1981 and 2010. Using unique personal identifiers, we match the birth records to a collection of additional administrative registers, such as the fertility register and national patient register. Thereby we can link each child to his or her parents and can follow it from birth to adulthood. Professionals in the health care sector and different authorities in the public sector report the data to Statistics Denmark. Statistics Denmark maintain the data and make it available for research purposes. Additionally, a great advantage of the data is the exceptional large sample size: we only experience attrition in the rare case of out-migration or death.

To construct the sample for the analysis, we use the following restrictions. We exclude families with at least one multiple birth (e.g., twins) as birth orders are more 
difficult to assign in these families. We keep only families with more than one child, families where all children have the same mother and father (biological siblings), and families with at least two children with non-missing birth outcomes. ${ }^{5}$ Due to reasons of space, we exclude families with five or more children from the analysis. ${ }^{6}$

Panel (a) in Table 1 shows the proportion of children of birth order one, two, three, and four. ${ }^{7}$ Having two children is the most popular family size. The average child in the sample lives in a family with 2.4 children with a median of two children. The frequency of parents with four children is low, less than two percent of all children are of birth order four. The share of boys and girls is statistically identical.

\section{[Table 1 about here.]}

The birth records contain a rich set of variables measuring different dimensions of child health at birth. Panel (b) in Table 1 provides descriptive statistics of these variables: mean birth weight in the sample is 3,530 grams; 3.1 percent of the children have low birth weight (birth weight $<2,500$ grams) and a similar share has high birth weight (birth weight $>4,500$ grams); and 4.1 percent of children are born premature (gestational age $<37$ weeks). To complement the anthropometric measures, we also consider the 5-minute Apgar score. ${ }^{8}$ With an average of 9.856 , the average nearly corresponds to 10, the maximum score possible. Given the highly skewed distribution of the Apgar score, we look at an indicator for low Apgar score (Apgar score $<7$ ) as a robustness check and obtain very comparable results. Given the large number of outcome measures and the potential concern of finding spurious correlations, we define a summary index following Kling et al. (2007) which is an equally weighted average of the standardized health outcomes (birth weight, low birth weight, high birth weight, prematurity, and Apgar score). We construct the index so that a higher value of the score reflects better health at birth. The health index has a mean of

\footnotetext{
${ }^{5}$ Missing information on health at birth results from (1) unrecorded data, which occasionally happens at the beginning of the data in 1981, (2) biological implausible values, and (3) non-existing information due to perinatal child death. When we look at the prenatal environment, we include information also for those children with missing birth outcomes to eliminate problems of selection.

${ }^{6}$ Our results also hold for families with five to eight children.

${ }^{7}$ We have fewer observations for birth order one due to a larger number of birth outcomes with missing information in the birth records, see footnote (6).

${ }^{8}$ The 5-minute Apgar score is a diagnostic test measured five minutes after birth and based on five criteria: heart rate, respiratory effort, muscle tone, reflex irritability, and color. For each criteria zero, one, or two points are assigned with the resulting score ranging between zero and ten. The Apgar score has been found to be highly correlated with cognitive ability, health and behavioral problems in later childhood (Almond et al., 2005). Considering the 1-minute Apgar score (measured one minute after birth) instead of the 5-minute Apgar score provides very comparable results. However, as the data does not provide us with the 1-minute Apgar score after 1996, we focus on the 5-minute Apgar score only.
} 
zero and a standard deviation of one. ${ }^{9}$

We have information on a rich set of prenatal maternal investments; these are summarized in panel (c) of Table 1. Maternal smoking information during pregnancy is available since 1991. The midwife reports the smoking status at every midwife visit. From this continuous reporting, we have information on whether a woman smoked anytime during pregnancy. For births in 1997 and later, we draw on additional smoking information. At the last midwife visit, usually within two weeks before birth, the midwife reports whether the woman still smokes and, if so, how many cigarettes she smokes daily. About 17 percent of all women smoked anytime during pregnancy using all information since 1991; restricting the sample to births from 1997 onwards, the share is slightly lower (13 percent), which is consistent with the wider awareness of the risks associated with smoking during pregnancy. At the end of pregnancy, around eleven percent of women still smoke. Four percent of all women smoke five or less cigarettes at the end of pregnancy and a similar share smokes six to ten cigarettes. Three percent of all women smoke eleven or more cigarettes at the last midwife visit. We group prenatal care into visits at the midwife and at the special practitioner (SP). Visits at the SP include, for instance, visits at the general practitioner, obstetrician, or gynecologist, i.e., medical contacts that relate to the pregnancy. Pregnant women see an SP about four times during pregnancy and the midwife five times. The number of visits has naturally changed over time. Today, the standard for an uncomplicated pregnancy is about three visits at the SP and six visits at the midwife. We account for changes in these behavioral dimensions over time by flexibly accounting for time effects in our empirical model. ${ }^{10}$

We also draw on information about prenatal maternal health. The bottom part of panel (c) shows summary statistics for hospitalizations for medical pregnancy complications, which we measure using three binary variables taking the value of one if the mother was hospitalized for that condition and zero otherwise. Hospitalizations for pregnancy complications constitute a very important dimension of maternal health because they capture actual complications that need to be treated in the hospital and are, thus, registered for every affected woman. ${ }^{11}$ Gestational diabetes is a form of diabetes in women without previously diagnosed diabetes.

\footnotetext{
${ }^{9}$ Using the first component of a principal component analysis of birth weight, low birth weight, high birth weight, prematurity, and Apgar score yields very similar results.

${ }^{10}$ Unfortunately, we do not observe alcohol consumption during pregnancy and are therefore unable to analyze this aspect of maternal behavior.

${ }^{11}$ Diagnoses are based on the International Statistical Classification of Diseases and Related Health Problems, $8^{\text {th }}$ and $10^{\text {th }}$ Revisions (ICD-8 and ICD-10). The reporting standard changed in 1994 from ICD-8 to the ICD-10 codes. However, we can still use information for all diagnoses in our sample, using the recoding of the old ICD-8 codes from Lykke et al. (2012) to merge with the ICD-10 codes.
} 
About one percent of all women are diagnosed with gestational diabetes. ${ }^{12}$ Gestational hypertension and preeclampsia are blood pressure disorders developing at near term. To be diagnosed with preeclampsia, the woman needs to have both gestational hypertension and proteinuria (large amount of protein in the urine). We define gestational hypertension conditional on not experiencing preeclampsia, as women with preeclampsia are necessarily also diagnosed with gestational hypertension in the same pregnancy. With this condition, we ensure not to capture an intermediate diagnosis for women who develop preeclampsia later in the same pregnancy. Less than one percent of all women are diagnosed with gestational hypertension, however, almost three percent experience preeclamspsia. ${ }^{13}$

\section{Empirical Strategy}

We now turn to our econometric model to examine the relationship between birth order and child health at birth. Our family fixed effects model takes the form:

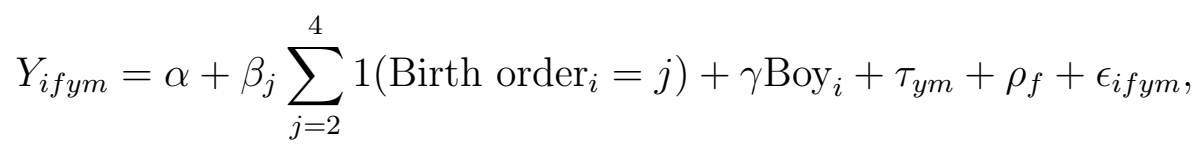

where $Y_{\text {ifym }}$ is health at birth of child $i$, born in family $f$, conceived in year $y$ and month $m$. The sum represents a set of birth order dummies, $1\left(\operatorname{Birth}_{\operatorname{order}_{i}}=j\right.$ ) for $j=2,3$, and 4 where $1(\cdot)$ is the indicator function. Children of birth order one represent the omitted category so that $\beta_{j}$, the vector of the coefficients of interest, captures differences with respect to birth order one. We flexibly account for time effects by including year of conception by month of conception dummies, $\tau_{y m}, \theta_{f}$ are family fixed effects, Boy ${ }_{i}$ is a dummy for being male, and $\epsilon_{i f y m}$ is the error term. Given the grouped structure of our data, standard errors are clustered at the family level to allow for serial correlation within families.

Identification is based on comparing second-, third-, and fourth-born children who are conceived across different years and months to firstborns within the same family. While family fixed effects control for any time-invariant observable and unobservable heterogeneity within families (i.e. final family size, maternal age at

\footnotetext{
${ }^{12}$ Casey et al. (1997) report that between one to three percent of all pregnancies in the U.S. are diagnosed with gestational diabetes.

${ }^{13}$ If women experiencing preeclampsia are counted, the figure for gestational hypertension would increase to four percent. Sibai (2003) notes a prevalence of gestational hypertension in the U.S. of 6 to 17 percent for nulliparous women and 2 to 4 percent for multiparous women. These numbers fit in line with the four percent given that we have 43 percent of nulliparous births and 57 percent of multiparous births in our sample.
} 
first birth, genetic endowments), controls for month and year of conception capture cohort and seasonal trends in the outcome variable. ${ }^{14}$ Hence, the coefficients, $\beta_{j}$, give us the effect of having a higher birth order within the family. To understand the mechanisms that explain the sign and the magnitude of $\beta_{j}$, we additionally estimate equation (1) with measures of maternal behavior and maternal health outcomes as the dependent variables.

\section{Birth Order and Health of Newborns}

In this section, we present the empirical analysis. We begin with a graphical inspection of the relationship between birth order and child health at birth before showing the estimation results. After having established the relationship between birth order and child health at birth, we turn to the potential mechanisms.

\section{$5.1 \quad$ Main Results}

Figure 1 plots the mean of the health at birth measures by birth order and family size (number of children) together with the 95 percent confidence interval. This approach allows us to show how health differences evolve across birth orders. In panel (a), (e), and (f), a higher value of the variable reflects better health, while the opposite is the case for the remaining panels. The non-parametric comparisons in Figure 1 show that birth order is positively correlated with birth weight (a) and Apgar score (e) and negatively correlated with low birth weight (b) and prematurity (d). Thereby Figure 1 demonstrates that health at birth improves with increasing birth order. For instance, compared to firstborns, birth weight increases on average by 140 to 160 grams, 200 to 210 grams, and 220 grams for birth order two, three, and four. These differences are somewhat comparable to the descriptive results from the medical literature (see, for instance, Magnus and Bjerkedal (1985) for Norway and Swamy et al. (2012) for the U.S.). In contrast, the positive relationship between birth order and high birth weight (c) indicates that for some children the positive effect on birth weight exceeds the value of what is considered healthy. Overall, these graphs indicate a positive relationship between health at birth and birth order: the results for the health index show improvements in the range of 10 to 20 percent of a standard deviation for later-born compared to firstborn children [panel (f)].

\footnotetext{
${ }^{14}$ We prefer the use of month of conception and year of conception over the use of month of birth and year of birth to compare children that have the same expected conditions in utero. This is in line with Almond and Mazumder (2011) and Persson and Rossin-Slater (2016). However, our results do not change when we substitute month of conception and year of conception with month of birth and year of birth, respectively.
} 
[Figure 1 about here.]

In Figure 1, we note three things regarding the shape of the birth order gradient. First, the largest change in health occurs between first- and second-born children. Second, the relationship between birth order and health at birth slightly reverts at the fourth birth for prematurity and low birth weight. However, the whiskers for the 95 percent confidence interval indicate that this slight reversion of the trend is not significant for low birth weight. Third, consistent with correlations shown in other studies, we find level differences between the three family sizes with children of larger families doing generally worse. However, the level differences are broadly constant across birth orders. Therefore, in the following, we pool all children but control for family-specific characteristics (by including family fixed effects). Nevertheless, as a robustness check of the regression results, we split the sample by family size.

[Table 2 about here.]

Table 2 presents the estimation results of equation (1). The simple correlations in Figure 1 are remarkably robust to controlling for gender, time, and family fixed effects; all birth order coefficients are statistically significant at the one percent level. However, compared to the simple correlations, the magnitude of the birth order differences are considerably larger. The point estimates imply that birth weight increases by 190 grams, 260 grams, and 310 grams for birth order two, three, and four compared to firstborns within the same family [column (1)]. The coefficients are jointly significantly different from zero and the increase for each additional birth order is significant at the one percent level. Similarly, the risks of low birth weight and prematurity are lower for later-borns than for firstborns [column (2)]. ${ }^{15}$ The positive association between birth order and child health unfolds, furthermore, in an increase in the Apgar score with higher birth order [column (4)]. However, a larger share of later-born children are also considered too heavy at birth; the prevalence of high birth weight increases by 2.0 to 3.8 percentage points for later-born children compared to firstborns in the same family.

Overall, the results in column (1) to (5) translate into a higher value of the standardized health index for birth order two, three, and four compared to firstborns in the same family [column (6)]. Accounting for gender, time, and family fixed effects more than doubles the effect of birth order on the health index: the results in column (6) imply more than a quarter of a standard deviation increase in the index for second-borns; more than a third of a standard deviation for third-borns;

\footnotetext{
${ }^{15}$ Except for the difference between birth order three and birth order four in column (4), the increase in the coefficients for each additional birth order is significant at the one percent level.
} 
and almost half a standard deviation for fourth-borns. In other words, the increase for birth order four is equivalent to moving someone from the middle of the health distribution $\left(50^{\text {th }}\right.$ percentile) to the $70^{\text {th }}$ percentile.

The positive effect of birth order on health of newborns is substantial, especially compared to other determinants of neonatal health. We show that being born second, third, or fourth reduces the probability of prematurity by 51 to 75 percent compared to firstborns in the same family; the reduction in low birth weight is even larger. In comparison, Currie and Walker (2011) find that the introduction of electronic toll collection reduces traffic congestion and vehicle emissions, resulting in a decrease of prematurity and low birth weight by respectively 10.8 percent and 11.8 percent among mothers living within two kilometers of a toll plaza compared to women living further away. Using variation in college openings, Currie and Moretti (2003) find that an additional year of maternal education reduces prematurity by around 5.6 percent and low birth weight by 9.3 percent. Deschênes et al. (2009) find that global climate change will increase the probability of low birth weight by 5.0 to 5.9 percent by the end of the century.

\section{Robustness Checks}

We have tested the robustness of our findings with several alternative specifications. While we control for maternal age at first birth in our main specification (contained in the family fixed effect), we did not account for maternal age at birth. In a family fixed effects model, maternal age at birth measures the age increase from the first to subsequent pregnancies, referred to as birth spacing, which is an endogenous decision. More importantly, controlling for maternal age (or birth spacing) would result in a bad control bias, if previous pregnancies affect birth spacing. Controlling very flexibly for maternal age (seven age dummies) or the interpregnancy interval (seven spacing dummies) does not affect the results. Similarly, accounting for income may result in a bad control bias. Yet again, controlling for different measures of income (household income, per capita disposable income, and parental labor earnings in the year before birth) does not change the results either.

The overall findings are insensitive to the definition of health at birth. Appendix Table A2 shows that for alternative definitions, we always find a positive relationship between birth order and health at birth. ${ }^{16}$ Moreover, selective mortality cannot explain the positive relationship. Perinatal mortality is negatively related to birth

\footnotetext{
${ }^{16}$ Additional measures for health at birth include the natural logarithm of birth weight and birth length, birth weight z-score, small for gestational age (SGA), large for gestational age (LGA), head circumference (available since 1997), and an indicator for being diagnosed for a condition relating to the perinatal period (available since 1994).
} 
order, eliminating a potential concern that the children we observe are positively selected. ${ }^{17}$ Finally, given that the risk of prematurity decreases with birth order, focusing on children with normal gestation (gestational age of 37 weeks or more) does not alter the results (results are available upon request).

\section{Heterogeneous Effects}

Heterogeneity in the effect of birth order on health at birth by family size could be at play, although we did not detect such heterogeneity in the descriptive graphs. For example, families that experience larger improvements in health at birth with increasing birth order might end up having more children in total. In other words, child health at birth could affect subsequent fertility. If this is the case, we should see that the coefficient for a specific birth order increases with family size.

[Table 3 about here.]

We test the heterogeneity in family size by estimating all regressions separately by the number of children in the family. To rule out families with incomplete fertility, we restrict the sample to families where the mother is at least 38 years by December 2010. ${ }^{18}$ Table 3 shows that a positive effect of birth order on health at birth exists for all family sizes. Moreover, the coefficients for a specific birth order are very similar across different family sizes. In conclusion, Table 3 does not reveal any evidence of selective fertility based on experienced births. Therefore, we continue to pool children from different family sizes.

Complementary heterogeneity analyses perpetuate that the positive effect of birth order on health of newborns is not subject to specific groups. Our data reveals a positive effect of birth order on child health at birth irrespective of maternal age at first birth, mother's education, and gender of the child. Appendix Figures A1 to A3 depict these subsample analyses graphically.

\footnotetext{
${ }^{17}$ Perinatal death is defined as fetal deaths occurring with a stated or presumed gestation of 28 weeks or more or deaths occurring within the first seven days of life. These children are grouped on the assumption that similar factors have caused the death (Barfield, 2011). The definition is furthermore the official definition for perinatal death used by the National Center for Health Statistic and the World Health Organization. Notice that we have more observations for perinatal deaths than for our other health outcomes, as not all children dying in the perinatal period have information on these other outcomes.

${ }^{18}$ The reason for this cut-off is that we observe births through December 31, 2010. This is a reasonable cut-off, as 91 percent of all women who were above 45 years in 2010 got their last child before the age of 38 . This restriction decreases modestly age at birth by roughly half a year and decreases the inter-pregnancy interval by 1.5 months.
} 


\subsection{Prenatal Environment}

To understand the origins of the positive relationship between birth order and health at birth, we here focus on the prenatal environment (maternal health behavior and maternal health outcomes) and ask whether and how this environment changes with subsequent pregnancies.

[Table 4 about here.]

Table 4 presents the effect of birth order on prenatal maternal smoking. Column (1) shows that the probability of smoking anytime during pregnancy decreases between 2.7 and 3.4 percentage points after the first pregnancy. We find a comparable effect focusing on smoking information from 1997 onwards: the probability to smoke during pregnancy falls by 2.9 to 3.8 percentage points (22 to 29 percent) in subsequent pregnancies compared to the first pregnancy [column (2)]. Columns (3) to (5) demonstrate that the lower probability to smoke at some point during pregnancy translates into fewer cigarettes smoked at the end of pregnancy. Interestingly, this last result includes women who smoke few cigarettes, five or less, and women who smoke a lot, eleven or more. Likewise, the likelihood of smoking at the end of pregnancy is lower in subsequent pregnancies than in the first [column (6)].

This last result stands in contrast to Black et al. (2016b). While the authors also find that women have a lower probability to smoke at the beginning of the pregnancy in later pregnancies compared to the first, they find that at the end of the pregnancy women in subsequent pregnancies have a higher probability to smoke. Similar to Lehmann et al. (2017), Black et al. (2016b) find that women are less likely to stop smoking in higher order pregnancies than in the first pregnancy conditional on smoking before or at the beginning of pregnancy. While Lehmann et al. (2017) focus on a small sample of retrospective questions about smoking, the data from Black et al. (2016b) is similar to ours (Norwegian register data covering a comparable time period). However, while the smoking information in Black et al. (2016b) comes from two time periods (the beginning and the end of pregnancy), the midwife reports smoking information during each visit in our data. ${ }^{19}$

\footnotetext{
${ }^{19}$ As the relationship in Table 4 column (6) is weaker than in column (2), these results indicate that some women quit smoking during pregnancy. Restricting the sample to women who smoked anytime in their first pregnancy, we continue to find that birth order has a negative effect on smoking at the end of pregnancy. We attempted to replicate the results from Black et al. (2016b) who study the probability to stop smoking conditional on smoking at the beginning of any pregnancy. To be able to estimate a family fixed effects model, this requires at least two observations within a family where the mother smoked at the beginning of the pregnancy (anytime during the pregnancy) and a variation in the probability to still smoke at the end. Even though this creates a very selected sample, we did not find that the order of the pregnancy (birth order) relates to the probability to stop smoking during pregnancy.
} 
Our result of a reduced probability to smoke in higher order pregnancies is consistent with the midwife altering the woman's information stock. For example, if a woman smokes during the first midwife visit, the midwife will inform the woman about the risks of smoking, advise her to quit smoking, and -importantly - continuous to do so during all the woman's visits. Viscusi et al. (1986) show that the stock of information about product hazards produces precautionary behavior. However, while the reduction in smoking is clear in our data, smoking alone cannot explain the positive relationship between birth order and child health. Lien and Evans (2005) and Del Bono et al. (2012) suggest that smoking during pregnancy reduces birth weight by around 200 grams. Using this estimate, smoking would explain on average a birth weight difference of $(200 \times 0.027 \approx) 5$ to $(200 \times 0.034 \approx) 7$ grams between firstborns and later-borns.

[Table 5 about here.]

Columns (1) and (2) of Table 5 present the effect of birth order on prenatal checkups. The number of checkups at the midwife falls modestly, by 0.1 to 0.3 visits during higher order pregnancies compared to the first; the number of checkups at the SP decreases somewhat more, by 0.2 and 0.4 visits. The literature often treats prenatal care as an investment (see, for instance, Buckles and Kolka, 2014; Lehmann et al., 2017). However, the effects of prenatal care on child health are elusive (Fiscella, 1995; Evans and Lien, 2005; Sonchak, 2014). Importantly, as Buckles and Kolka (2014) point out, a change in the demand for prenatal care across different pregnancies might reflect a change in the beliefs and expectations about prenatal care. ${ }^{20}$

Based on Arrow (1963), Dardanoni and Wagstaff (1990) show theoretically that the demand for medical care falls if uncertainty about the effectiveness of medical care decreases or if individuals become better informed about health outcomes, e.g., due to greater confidence in self-diagnosis. This implies that the demand for prenatal checkups falls if (1) checkups in the first pregnancy provide increased knowledge about their effectiveness and (2) a woman learns about her own health and child health at birth through observations during the first pregnancy. As we use data from a country with universal health care, financial constraints are not likely to play an important role for access to prenatal care. Hence, a reduction in the number of checkups could be an efficient response to experiences in the first pregnancy and

\footnotetext{
${ }^{20}$ Because information on both prenatal smoking and prenatal care is available only for a subsample of all children, we test the robustness of our findings towards estimating the effect of birth order on child health at birth for the sample of children for which we have this information (common sample). Our results are robust to this exercise.
} 
would not harm the unborn child. In addition to being a choice, prenatal checkups might also be the result of underlying maternal health. Moreover, if the argument about a change in beliefs and expectations is true, the reduction in the number of checkups in higher order pregnancies should not be associated with worse maternal health.

Columns (3) to (5) of Table 5 show the effect of birth order on maternal health. The results reveal a significant and large reduction in the probability of suffering from gestational diabetes, gestational hypertension, and preeclampsia with higher order pregnancies compared to the first pregnancy. Thus, women are less likely to experience severe pregnancy complications in later pregnancies, indicating better maternal health. While the prevalence of gestational diabetes, gestational hypertension, or preeclampsia are rare in the population, they provide a well-measured proxy for maternal health.

But why should maternal health improve with subsequent pregnancies? The reduction in smoking may be one reason - other behavioral factors may be important as well. For example, parents' social values may change with higher order pregnancies; but as the in utero environment is not shaped by parent-child interactions, the inability to control for social values should not affect our results. Another example is a potential change in the stress level during pregnancy. Deaton and Stone (2014) find that parents experience more daily joy and more daily stress than non-parents. However, we can refute the concern of stress playing a role by looking at quasiexperimental evidence. Persson and Rossin-Slater (2016) find that the death of a close relative during pregnancy, a very severe type of stress, increases prematurity by 0.6 percentage points. In comparison, we see that firstborns face an increased risk of 2.2 to 2.9 percentage points (all effects compared to a mean of 4 percent). Using a similar empirical strategy, Black et al. (2016a) find no effect on the Apgar score. Hence, stress can neither be a strong mechanism nor a strong confounding factor. While our data does not enable us to look more into this question of why maternal health improves, the medical literature provides a compelling hypothesis for the improvements in maternal health that fits our findings well. Gluckman and Hanson (2004) argue that higher order pregnancies face lower constraints that positively influence fetal growth. Responsible for this observation are physiological changes unrelated to maternal behavior that improve with subsequent pregnancies. Appendix A.1 outlines the arguments in more detail.

Summing up, to understand the negative effect of birth order on educational outcomes later in life, we have studied birth order differences in health at birth and in the prenatal environment. Our results imply that the negative relationship 
between birth order and education cannot be explained by health differences at birth. Moreover, we do not find indications that prenatal investments favor firstborns.

\section{Health from Birth through Childhood}

The results from the previous section raise the inevitable question about how birth order differences in health evolve between birth and adolescence. In this section, we answer part of this question by studying birth order differences in hospital admissions. Our data enables us to observe diagnoses from inpatient and outpatient hospital admissions as well as emergency room contacts for the children in the health-at-birth-sample throughout childhood, i.e., from age 1 through 16. Because the classification system changed in Denmark in 1994 from ICD-8 to ICD-10, we focus on hospital admissions from 1994 to 2011 but include all children born between 1981 and $2010 .^{21}$

From the hospitalization data, we define two outcomes. Our first measure captures general health conditions and includes all hospitalizations except injuries and other external causes of morbidity and mortality (ICD-10 diagnosis codes chapter $\mathrm{I}-\mathrm{XIV}[\mathrm{A}-\mathrm{N}]) .{ }^{22}$ This measure excludes injuries and other external causes, because they do not necessarily capture a general health condition. Moreover, injuries may be indicative of differences in the personality of the children, parental supervision, or an older sibling's influence, such as playing wildly with the younger sibling. As hospitalizations for injuries are interesting per se, they constitute our second outcome (ICD-10 diagnosis codes XIX [S, T0-14]). For each of these two types of hospitalization, we consider whether a child was hospitalized at each age from age 1 through 16.

Table 6 shows that the probability of being admitted due to a general health condition is 8.2 percent at any given age, ranging between 6 percent (at age 7 ) to 15 percent (at age 1). The average likelihood of being in contact with the hospital due to an injury is 12.4 percent across all age groups with the lowest probability being

\footnotetext{
${ }^{21}$ Due to the restriction of the hospital admission data, we do not observe the oldest cohorts when they are young. For example, the cohort born in 1981 will be observed from age 13 onwards.

${ }^{22} \mathrm{We}$ also exclude conditions related to pregnancy and childbirth as well as congenital malformations and conditions originating from the perinatal period to not confuse this analysis with the health at birth analysis. We include chapters I) Certain infections and parasitic diseases, II) Neoplasms, III) Diseases of the blood and blood-forming organs and certain diseases, IV) Endocrine, nutritional and metabolic diseases, V) Mental and behavioral disorders, VI) Diseases of the nervous system, VII) Diseases of the eye and adnexa, VIII) Diseases of the ear and mastoid process, IX) Diseases of the circulatory system, X) Diseases of the respiratory system, XI) Diseases of the digestive system, XII) Diseases of the skin and subcutaneous tissue, XIII) Diseases of the musculoskeletal system and connective tissue, XIV) Diseases of the genitourinary system.
} 
9 percent (around age 6). We have about 600,000 children in each age group from age 1 through 13 and 400,000 to 500,000 children in the age group 14 through 16 .

[Table 6 about here.]

To examine the evolution of birth order differences in health throughout childhood, we interact the birth order dummies in equation (1) with dummies for each age. In addition, we include family-specific age effects by interacting the family fixed effects with the age dummies, gender-specific age effects, and time-specific age effects. We continue to cluster standard errors at the family level. Hence, we estimate a fully interacted age model of the following form:

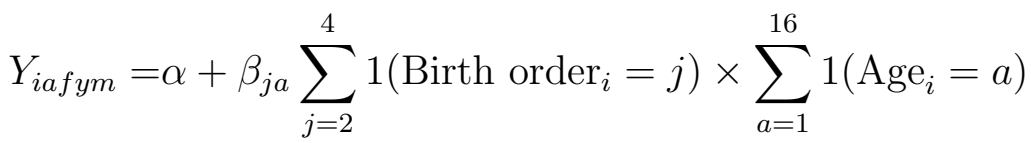

$$
\begin{aligned}
& +\gamma_{a} \mathrm{Boy}_{i}+\tau_{y m a}+\rho_{f a}+\epsilon_{i a f y m},
\end{aligned}
$$

$\beta_{j a}$ are our coefficients of interest and constitute the effects of being born second, third, or fourth on the probability of a hospitalization at age $a$ compared to firstborns at the same age.

Figure 2 presents the result of estimating model 2 for hospitalizations reflecting general health conditions. The dot markers depict the point estimates and the whiskers indicate the 95 percent confidence interval of the interaction between birth order and age dummies. Note that the three graphs in Figure 2 are from one regression. For convenience, we present the results separately for birth order two, three, and four [panels (a), (b), and (c), respectively]. Appendix Table A3 presents the results in a table, together with the p-values of Wald tests testing the equality of two successive coefficients. Our results show an early life health advantage of laterborns compared to firstborns. The advantage is largest around age three, where later-borns are 0.8 to 1.4 percentage points less likely to have a contact with the hospital for general health conditions. Given a mean of 8.4 percent, this represents a reduction of 9.5 to 16.7 percent.

After age four, the advantage of later-borns substantially weakens and eventually becomes insignificant from age seven onwards. For example, at age 12 the point estimates are in the range of -0.079 and 0.042 percentage points. Between age 7 and 12 , the equality of the point estimates cannot be rejected ( $\mathrm{p}$-value of Wald test is 0.70, 0.90, and 0.92 for birth order two, three, and four). However, at age 13, the point estimates are positive for all birth orders and are significantly larger compared to the effects at age 12: later-borns are 0.3 to 1.3 percentage points (5.1 to 22.0 
percent) more likely to be admitted to a hospital for general health conditions. This later-born disadvantage prevails until age 16 . While at age 15 , the point estimates are imprecisely estimated, the estimates are not significantly different from those at age 14 or 16 . Overall, we cannot reject the equality of the point estimates for age 13 to 16 for any birth order (p-values of Wald tests are $0.63,0.66$, and 0.74 for birth order two, three, and four).

[Figure 2 about here.]

Figure 3 presents the effect of birth order on injuries between age 1 and 16 . In contrast to hospitalizations for health conditions, we see an early life disadvantage of second-, third-, or fourth-born children compared to firstborns: later-born children are more likely to suffer an injury than firstborns at the same age. For example, at age four, the risk of being admitted to the hospital for injuries are 18 percent, 23 percent, and 31 percent higher for second-, third-, and fourth-born children, respectively, compared to firstborns at the same age. However, by age seven, the effect weakens and remains small until age 12. Between age 7 and 12, we cannot reject the equality of the point estimates (p-values of Wald tests are 0.54, 0.93, and 0.67 for birth order two, three, and four). This pattern is comparable to Figure 2 in the sense that between age 7 and 12, the birth order differences in hospitalizations are the smallest. Around age 13, in the early teenage years, birth order differences start to increase. At age 14, the probability of suffering an injury is 8, 14, and 29 percent higher for second-, third-, and fourth-born children, respectively, compared to firstborns at the same age. ${ }^{23}$

[Figure 3 about here.]

Our results show that, in terms of general health conditions in early childhood, later-born children have a health advantage compared to firstborns. This advantage is in line with the positive effect of birth order on child health at birth found in the previous section. Moreover, the weakening of the effect and its reversal in favor of firstborns links this paper to the large economics literature that finds a firstborn advantage in educational outcomes in adolescence. The results on injuries further show that, overall, later-born children behave more risky throughout childhood. While we do not know whether this difference in behavior stems from differences in the personality of the children, parental supervision, or influence of older siblings, our

\footnotetext{
${ }^{23}$ We find a similar result when considering emergency room contacts instead of hospitalizations for injuries, underlining that the health disadvantage of later-borns stems from acute rather than chronic diseases.
} 
results on health throughout childhood cannot dismiss the hypothesis that postnatal investments differ for firstborns and later-borns (see for instance Price, 2008; Hotz and Pantano, 2015; Lehmann et al., 2017). In addition, the large positive effect of birth order on injuries in the teenage years is consistent with findings in Argys et al. (2006) and Averett et al. (2011) that later-borns are much more likely to smoke cigarettes or marijuana, drink alcohol, and engage in sexual activities. The teenage year results are also in line with a recent working paper (Lundberg and Svaleryd, 2016) that follow a similar approach to ours. ${ }^{24}$

\section{Conclusions}

Our study provides new evidence on the relationship between birth order and child health using a unique dataset from Denmark. Using family fixed effects models, we find a large and positive relationship between birth order and child health at birth that is robust to the way we define health at birth and that holds irrespective of family size. In terms of prenatal investments, we show that women are more likely to smoke in their first compared to subsequent pregnancies. Moreover, women more often visit their midwife and medical doctor during their first pregnancy. While this behavior can be interpreted as behavior that is more cautious in the first pregnancy, it is also indicative of a higher demand for medical care due to worse health. Using data on hospitalizations for medical pregnancy complications, we show that maternal health improves with subsequent pregnancies. An improvement in maternal health with higher order pregnancies is consistent with a biological mechanism that improves maternal health with consecutive pregnancies. Looking at hospitalizations for general health conditions in childhood between age 1 and 16, we show that the health disadvantage of firstborns persists in the first years of life. However, the effect weakens around age seven and the results indicate a firstborn health advantage in adolescence. In contrast, throughout childhood, later-borns are more likely to suffer an injury. The results on health in adolescence are in line with the negative effect of birth order on educational outcomes found in previous studies and with the hypothesis that postnatal investments differ between first- and later-born children.

Studying health in adulthood (around age 40), Black et al. (2016b) also distinguish between birth order differences in general health conditions and risky health behavior. The authors find that while firstborns are less healthy than later-borns (with respect to high blood pressure, high levels of triglycerides, and obesity), later-

\footnotetext{
${ }^{24}$ Lundberg and Svaleryd (2016) group children into larger age groups and focus on inpatient contacts to the hospital only. While the authors also study health differences in early childhood, they do not find a robust firstborn advantage in hospitalizations before age six.
} 
borns behave more risky in terms of smoking and alcohol consumption. While Black et al. (2016b) cannot provide an answer to this puzzle, our results are consistent with their findings. We find that throughout childhood, later-borns have a higher risk of suffering an injury, but firstborns are overall less healthy at birth and in early childhood. For example, firstborns have a higher risk of low birth weight than their later-born siblings. Importantly, the medical literature finds that health disadvantages at birth become apparent again later in life; reduced fetal growth is, for instance, associated with metabolic and cardiovascular diseases in adulthood (Barker et al., 1993a,b; Barker, 1995). Future research may wish to better understand how birth order differences in child health relate to birth order differences in educational outcomes and health later in life. 


\section{References}

Arrow, K. J. (1963). "Uncertainty and the Demand for Medical Care". American Economic Review 53.(5), pp. 941-973.

Woessner, J. F. and T. H. Brewer (1963). "Formation and Breakdown of Collagen and Elastin in the Human Uterus During Pregnancy and Post-Partum Involution." The Biochemical Journal 89, pp. 75-82.

Camilleri, A. P. and V Cremona (1970). "The Effect of Parity on Birthweight". The Journal of Obstetrics and Gynaecology of the British Commonwealth 77.(2), pp. $145-7$.

Warburton, D and A Naylor (1971). "The Effect of Parity on Placental Weight and Birth Weight: An Immunological Phenomenon? A Report of the Collaborative Study of Cerebral Palsy". American Journal of Human Genetics 23.(1), pp. 4154.

Chakraborty, R, S. R. Das, M Roy, B. N. Mukherjee, and S. K. Das (1975). "The Effect of Parity on Placental Weight and Birth Weight: Interaction with Placental Alkaline Phosphatase Polymorphism". Annals of Human Biology 2.(3), pp. 227234.

Magnus, P. and T. Bjerkedal (1985). "The Association of Parity and Birth Weight: Testing the Sensitization Hypothesis". Early Human Development 12, pp. 49-54. Behrman, J. R. and P. Taubman (1986). "Birth Order, Schooling, and Earnings". Journal of Labor Economics 4.(3, Part 2), pp. 121-50.

Viscusi, W. K., W. a. Magat, and J. Huber (1986). "Informational Regulation of Consumer Health Risks: An Empirical Evaluation of Hazard Warnings". Rand Journal of Economics 17.(3), pp. 351-365.

Behrman, J. R. (1988). "Intrahousehold Allocation of Nutrients in Rural India: Are Boys Favored? Do Parents Exhibit Inequality Aversion?" Oxford Economic Papers 40.(1), pp. 32-54.

Sørnes, T and T Bakke (1989). "Uterine Size, Parity and Umbilical Cord Length". Acta Obstetricia et Gynecologica Scandinavica 68.(5), pp. 439-441.

Dardanoni, V. and A. Wagstaff (1990). "Uncertainty and the Demand for Medical Care". Journal of Health Economics 9.(1), pp. 23-38.

Barker, D. J., C. N. Martyn, C Osmond, C. N. Hales, and C. H. Fall (1993a). "Growth in Utero and Serum Cholesterol Concentrations in Adult Life". British Medical Journal 307.

Barker, D. J., C Osmond, S. J. Simmonds, and G. A. Wield (1993b). "The Relation of Small Head Circumference and Thinness at Birth to Death from Cardiovascular Disease in Adult Life". British Medical Journal 306. 
Barker, D. J. (1995). "The Fetal Origins of Coronary Heart Disease". British Medical Journal 311.(6998), pp. 171-4.

Fiscella, K. (1995). "Does Prenatal Care Improve Birth Outcomes? A Critical Review". Obstetrics and Gynecology 85, pp. 468-479.

Casey, B. M., M. J. Lucas, D. D. McIntire, and K. Leveno (1997). "Pregnancy Outcomes in Women with Gestational Diabetes Compared With the General Obstetric Population". Obstetrics and Gynecology 90.(6), pp. 869-873.

Hafner, D. E., K. Schuchter, M. Metzenbauer, and K. Philipp (2000). "Uterine Artery Doppler Perfusion in the First and Second Pregnancies". Ultrasound in Obstetrics and Gynecology 16.(7), pp. 625-629.

Currie, J. and E. Moretti (2003). "Mother's Education and the Intergenerational Transmission of Human Capital: Evidence from College Openings". The Quarterly Journal of Economics 118.(4), pp. 1495-1532.

Hollis, B, F Prefumo, A Bhide, S Rao, and B Thilaganathan (2003). "First-Trimester Uterine Artery Blood Flow and Birth Weight". Ultrasound in Obstetrics \& Gynecology 22.(4), pp. 373-376.

Johanson, J. M. and P. J. Berger (2003). "Birth Weight as a Predictor of Calving Ease and Perinatal Mortality in Holstein Cattle". Journal of Dairy Science 86.(11), pp. 3745-3755.

Khong, T. Y., E. D. Adema, and J. J. H. M. Erwich (2003). "On an Anatomical Basis for The Increase in Birth Weight in Second and Subsequent Born Children". Placenta 24.(4), pp. 348-353.

Plug, E. and W. Vijverberg (2003). "Schooling, Family Background, and Adoption: Is It Nature or Is It Nurture?" Journal of Political Economy 111.(3), pp. 611-641. Sibai, B. M. (2003). "Diagnosis and Management of Gestational Hypertension and Preeclampsia". Obstetrics and Gynecology 102.(1), pp. 181-192.

Behrman, J. R. and M. R. Rosenzweig (2004). "Returns to Birthweight". The Review of Economics and Statistics 86.(2), pp. 586-601.

Ejrnæs, M. and C. Pörtner (2004). "Birth Order and the Intrahousehold Allocation of Time and Education". The Review of Economics and Statistics 86.(4), pp. 10081019.

Gluckman, P. and M. Hanson (2004). The Fetal Matrix: Evolution, Development and Disease. Cambridge, UK: Cambridge University Press.

Prefumo, F., A. Bhide, S. Sairam, L. Penna, B. Hollis, and B. Thilaganathan (2004). "Effect of Parity on Second-Trimester Uterine Artery Doppler Flow Velocity and Waveforms". Ultrasound in Obstetrics and Gynecology 23.(1), pp. 46-49. 
Almond, D., K. Y. Chay, and D. S. Lee (2005). "The Costs of Low Birth Weight". The Quarterly Journal of Economics 120.(3), pp. 1031-1083.

Evans, W. N. and D. S. Lien (2005). "The Benefits of Prenatal Care: Evidence from the PAT Bus Strike". Journal of Econometrics 125.(1-2), pp. 207-239.

Lien, D. S. and W. N. Evans (2005). "Estimating the Impact of Large Cigarette Tax Hikes: The Case of Maternal Smoking and Infant Birth Weight". Journal of Human Resources 40.(2), pp. 373-392.

Argys, L. M., D. I. Rees, S. L. Averett, and B. Witoonchart (2006). "Birth Order and Risky Adolescent Behavior". Economic Inquiry 44.(2), pp. 215-233.

Kantarevic, J. and S. Mechoulan (2006). "Birth Order, Educational Attainment, and Earnings: An Investigation Using the PSID". Journal of Human Resources 41.(4), pp. $755-777$.

Cunha, F. and J. Heckman (2007). "The Technology of Skill Formation". The American Economic Review 97.(2), pp. 31-47.

Gardner, D. S., P. J. Buttery, Z. Daniel, and M. E. Symonds (2007). "Factors Affecting Birth Weight in Sheep: Maternal Environment". Reproduction 133.(1), pp. 297-307.

Kling, J. R., J. B. Liebman, and L. F. Katz (2007). "Experimental Analysis of Neighborhood Effects". Econometrica 75.(1), pp. 83-119.

Kristensen, P. and T. Bjerkedal (2007). "Explaining the Relation Between Birth Order and Intelligence". Science 316, p. 2007.

Sulloway, F. (2007). "Birth Order and Intelligence". Science 316.(5832), pp. 1711-2.

Price, J. (2008). "Parent-Child Quality Time: Does Birth Order Matter?" Journal of Human Resources 43.(1), pp. 240-265.

Deschênes, O., M. Greenstone, and J. Guryan (2009). "Climate Change and Birth Weight". The American Economic Review 99.(2), pp. 211-217.

Almond, D and B Mazumder (2011). "Health Capital and the Prenatal Environment: The Effect of Ramadan Observance During Pregnancy". American Economic Journal: Applied Economics 3.(4), pp. 56-85.

Averett, S. L., L. M. Argys, and D. I. Rees (2011). "Older Siblings and Adolescent Risky Behavior: Does Parenting Play a Role?" Journal of Population Economics 24.(3), pp. 957-978.

Barfield, W. D. (2011). "Standard Terminology for Fetal, Infant, and Perinatal Deaths". Pediatrics 128.(1), pp. 177-181.

Black, S. E., P. J. Devereux, and K. G. Salvanes (2011). "Older and Wiser? Birth Order and IQ of Young Men". CESifo Economic Studies 57.(1), pp. 103-120. 
Currie, J. and R. Walker (2011). "Traffic Congestion and Infant Health: Evidence from E-ZPass". American Economic Journal: Applied Economics 3, pp. 65-90.

Del Bono, E., J. Ermisch, and M. Francesconi (2012). "Intrafamily Resource Allocations: A Dynamic Structural Model of Birth Weight". Journal of Labor Economics 30.(3), pp. 657-706.

Lykke, J. A., M. J. Paidas, E. W. Triche, and J. Langhoff-Roos (2012). "Fetal Growth and Later Maternal Death, Cardiovascular Disease and Diabetes". Acta Obstetricia et Gynecologica Scandinavica 91.(4), pp. 503-510.

Swamy, G., S. Edwards, A. Gelfand, S. James, and M. L. Miranda (2012). "Maternal Age, Birth Order, and Race: Differential Effects on Birthweight". Journal of Epidemiology and Community Health 66.(2), pp. 136-42.

Buckles, K. S. and S. Kolka (2014). "Prenatal Investments, Breastfeeding, and Birth Order". Social Science \& Medicine 118, pp. 66-70.

Deaton, A. and A. Stone (2014). "Evaluative and Hedonic Wellbeing Among Those With and Without Children at Home". Proceedings of the National Academy of Sciences, pp. 1-6.

Figlio, D. N., J. Guryan, K. Karbownik, and J. Roth (2014). "The Effects of Poor Neonatal Health on Children's Cognitive Development". American Economic Review 104.(12), pp. 3921-3955.

Hinkle, S. N., P. S. Albert, P. Mendola, L. A. Sjaarda, E. Yeung, N. S. Boghossian, and S. K. Laughon (2014). "The Association Between Parity and Birthweight in a Longitudinal Consecutive Pregnancy Cohort". Paediatric and Perinatal Epidemiology 28.(2), pp. 106-15.

Sonchak, L. (2014). "Medicaid Reimbursement, Prenatal Care and Infant Health". Journal of Health Economics 44, pp. 10-24.

Hotz, V. J. and J. Pantano (2015). "Strategic Parenting, Birth Order, and School Performance". Journal of Population Economics 28.(4), pp. 911-936.

Black, S. E., P. J. Devereux, and K. G. Salvanes (2016a). "Does Grief Transfer across Generations? Bereavements during Pregnancy and Child Outcomes". American Economic Journal: Applied Economics 8.(1), pp. 193-223.

Black, S. E., P. J. Devereux, and K. G. Salvanes (2016b). "Healthy (?), Wealthy, and Wise: Birth Order and Adult Health". Economics \& Human Biology 23, pp. $27-45$.

Lundberg, E. and H. Svaleryd (2016). "Birth Order and Child Health". Lund University Labour Market and Discrimination Studies, 2016:4. 
Persson, P. and M. Rossin-Slater (2016). "Family Ruptures, Stress, and the Mental Health of the Next Generation". NBER Working Paper Series No. 22229, May 2016.

Lehmann, J.-Y. K., A. Nuevo-Chiquero, and M. Vidal-Fernandez (2017). "The Early Origins of Birth Order Differences in Children's Outcomes and Parental Behavior". Journal of Human Resources (forthcoming).

Pavan, R. (2017). "On The Production of Skills and the Birth Order Effect". Journal of Human Resources (forthcoming). 
Figure 1

Birth Outcomes by Birth Order and Family Size

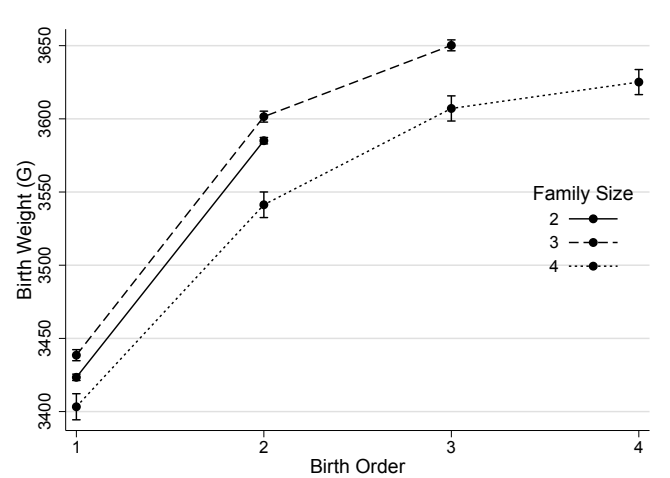

(a) Birth weight (in grams)

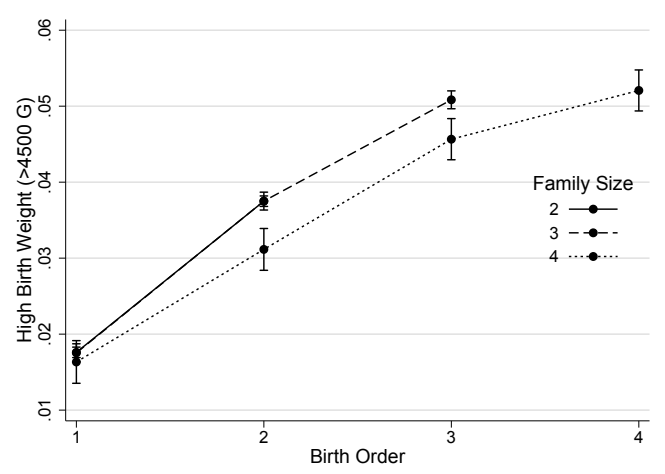

(c) High birth weight (> 4500 grams)

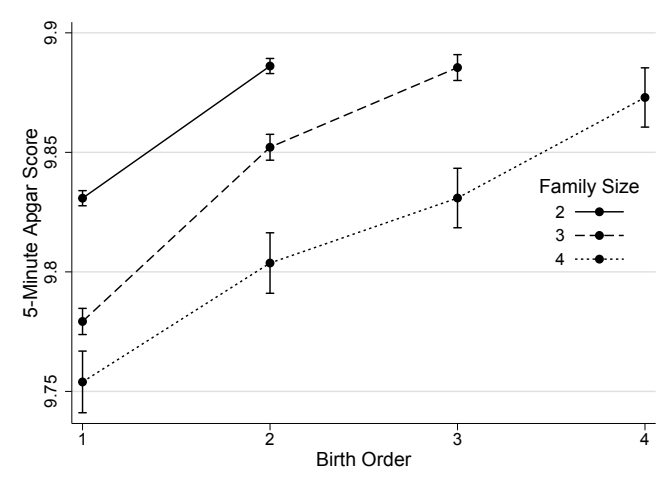

(e) 5-minute Apgar score

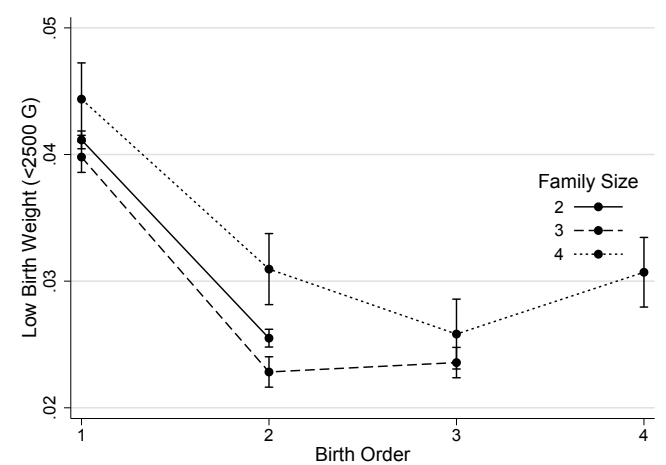

(b) Low birth weight $(<2500$ grams $)$

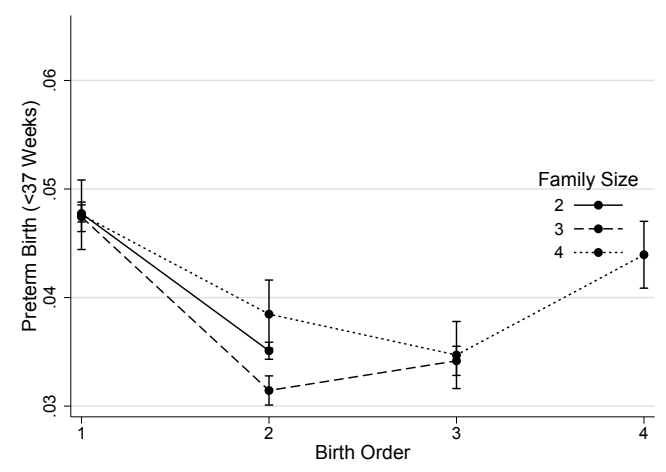

(d) Prematurity ( $<37$ weeks)

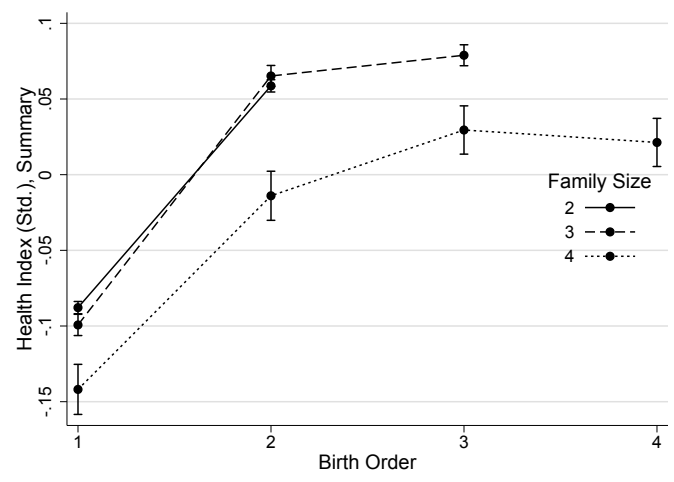

(f) Health index

Notes: The figure plots the raw means of the variables by birth order and family size. The health index (mean of zero and standard deviation of one) is an equally weighted summary index of the following variables: birth weight, low birth weight, high birth weight, prematurity, and Apgar score. The point markers indicate the means, the whiskers represent the 95 percent confidence intervals for the means. 


\section{Figure 2}

Hospitalizations for Health Conditions Throughout Childhood by Birth Order

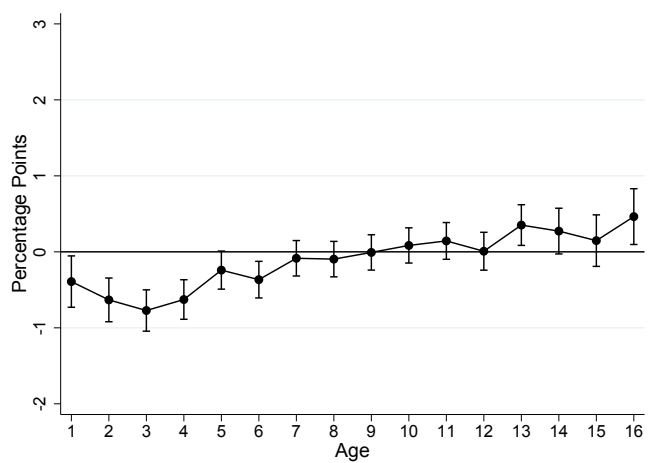

(a) Birth order 2

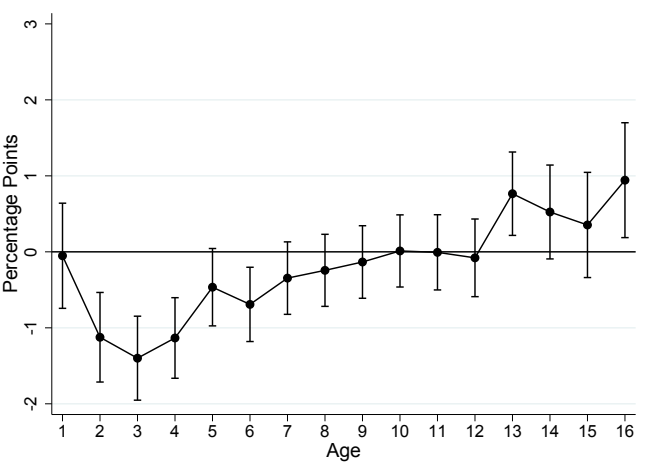

(b) Birth order 3

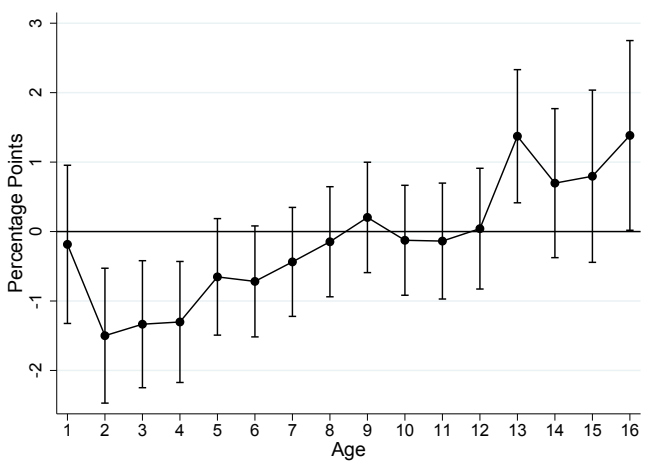

(c) Birth order 4

Notes: The figure plots the evolution of the birth order differences in hospitalizations for health conditions from age 1 through 16 (probability of hospitalization at each age for ICD-10 diagnosis codes chapter I-XIV $[\mathrm{A}-\mathrm{N}]$ ). The dot markers represent the point estimates, which we scaled to percentage points $(\times 100)$. The whiskers represent the 95 percent confidence intervals. The regression includes interactions of all age dummies with family indicators, year by month of conception dummies, and a dummy for gender of the child. The omitted category is birth order one. Included in the sample are all observations from families with at least two children with non-missing hospitalization records at a given age of the children. 


\section{Figure 3}

Hospitalizations for Injuries Throughout Childhood by Birth Order

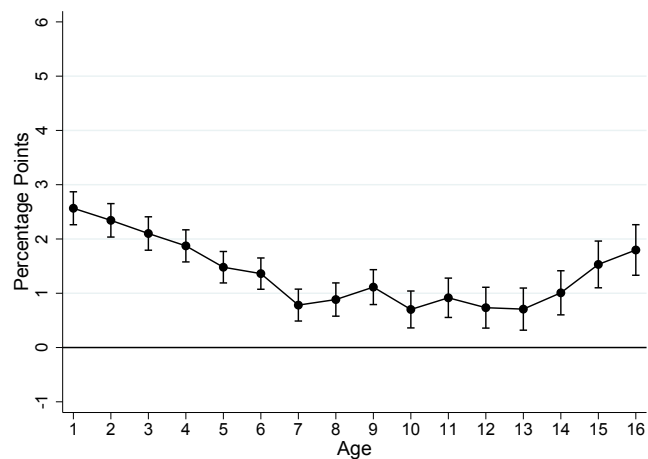

(a) Birth order 2

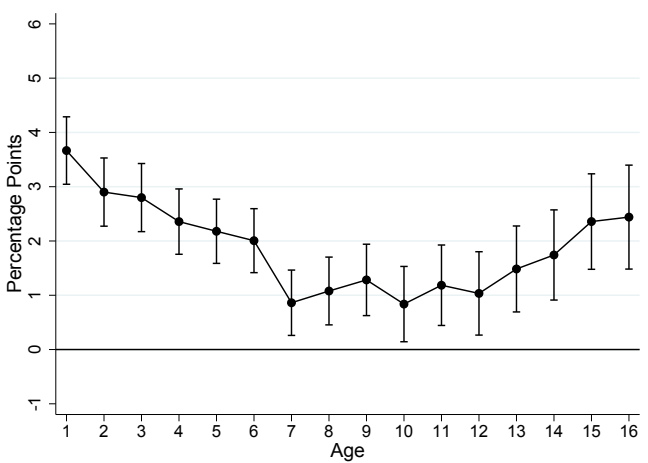

(b) Birth order 3

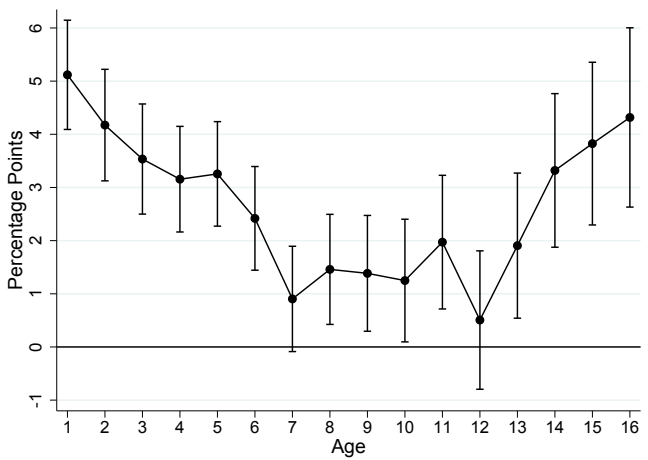

(c) Birth order 4

Notes: The figure plots the evolution of the birth order differences in hospitalizations for injuries from age 1 to 16 (probability hospitalization at each age, ICD-10 diagnosis codes XIX [S, T0-14]). The dot markers represent the point estimates, which we scaled to percentage points $(\times 100)$. The whiskers represent the 95 percent confidence intervals. The regression includes interactions of all age dummies with family indicators, year by month of conception dummies, and a dummy for gender of the child. The omitted category is birth order one. Included in the sample are all observations from families with at least two children with non-missing hospitalization records at a given age of the children. 
Table 1

Child Characteristics and Prenatal Environment of Analysis Sample

\begin{tabular}{|c|c|c|c|}
\hline Variable & Mean & S.D. & $\mathrm{N}$ \\
\hline \multicolumn{4}{|l|}{ (a) Demographic characteristics } \\
\hline Number of children in family & 2.439 & 0.622 & $1,085,598$ \\
\hline Birth order 1 & 0.430 & 0.495 & $1,085,598$ \\
\hline Birth order 2 & 0.433 & 0.496 & $1,085,598$ \\
\hline Birth order 3 & 0.118 & 0.323 & $1,085,598$ \\
\hline Birth order 4 & 0.018 & 0.134 & $1,085,598$ \\
\hline Child is male & 0.514 & 0.500 & $1,085,598$ \\
\hline Month of conception & 6.709 & 3.424 & $1,085,598$ \\
\hline Year of conception & 1995.971 & 7.636 & $1,085,598$ \\
\hline \multicolumn{4}{|l|}{ (b) Birth outcomes } \\
\hline Birth weight (in grams) & 3530.691 & 551.172 & $1,085,598$ \\
\hline Low birth weight (< 2500 grams) & 0.031 & 0.173 & $1,085,598$ \\
\hline High birth weight ( $>4500$ grams) & 0.031 & 0.173 & $1,085,598$ \\
\hline Prematurity $(<37$ weeks $)$ & 0.041 & 0.198 & $1,085,598$ \\
\hline 5-Minute Apgar Score & 9.856 & 0.748 & $1,085,598$ \\
\hline \multicolumn{4}{|l|}{ (c) Prenatal environment } \\
\hline Smoking anytime (since 1991) & 0.165 & 0.371 & 726,743 \\
\hline Smoking anytime (since 1997) & 0.133 & 0.339 & 476,865 \\
\hline Smokes at the end of pregnancy & 0.114 & 0.318 & 476,865 \\
\hline Smokes $\leq 5$ cigarettes a day & 0.040 & 0.197 & 476,865 \\
\hline Smokes $\overline{6}-10$ cigarettes a day & 0.042 & 0.201 & 476,865 \\
\hline Smokes $\geq 11$ cigarettes a day & 0.029 & 0.168 & 476,865 \\
\hline \# Prenatal checkups special practitioner (SP) & 4.121 & 2.100 & $1,031,509$ \\
\hline \# Prenatal checkups midwife & 4.850 & 1.996 & $1,077,891$ \\
\hline Gestational diabetes & 0.012 & 0.107 & $1,105,306$ \\
\hline Gestational hypertension & 0.009 & 0.092 & $1,105,306$ \\
\hline Preeclampsia & 0.029 & 0.168 & $1,105,306$ \\
\hline
\end{tabular}

Notes: The table shows summary statistics for the sample used in the empirical analysis. Panels (a) and (b) include all observations for families with at least two children with non-missing birth outcomes. Panel (c) also includes observations for those children with missing birth outcomes to eliminate problems of selection. Information on prenatal smoking is available since 1991 and since 1997, more detailed smoking information is available. We always exclude families with multiple birth and only-child families, and we keep only families where all children have the same mother and father (biological siblings). 
Table 2

Effect of Birth Order on Child Health at Birth

\begin{tabular}{|c|c|c|c|c|c|c|}
\hline & $\begin{array}{l}\text { Birth weight } \\
\quad \text { (grams) }\end{array}$ & $\begin{array}{l}\text { Low birth weight } \\
(<2500 \text { grams })\end{array}$ & $\begin{array}{l}\text { High birth weight } \\
\text { (> }>4500 \text { grams })\end{array}$ & $\begin{array}{l}\text { Prematurity } \\
(<37 \text { weeks })\end{array}$ & Apgar score & Health index \\
\hline & $(1)$ & $(2)$ & $(3)$ & $(4)$ & $(5)$ & $(6)$ \\
\hline Birth order 2 & $\begin{array}{c}185.848^{* * *} \\
(1.548)\end{array}$ & $\begin{array}{c}-0.026^{* * *} \\
(0.001)\end{array}$ & $\begin{array}{l}0.020^{* * *} \\
(0.001)\end{array}$ & $\begin{array}{l}-0.025^{* * *} \\
(0.001)\end{array}$ & $\begin{array}{l}0.128^{* * *} \\
(0.003)\end{array}$ & $\begin{array}{l}0.279^{* * *} \\
(0.003)\end{array}$ \\
\hline Birth order 3 & $\begin{array}{l}261.135^{* * *} \\
(3.238)\end{array}$ & $\begin{array}{l}-0.037^{* * *} \\
(0.001)\end{array}$ & $\begin{array}{l}0.033^{* * *} \\
(0.001)\end{array}$ & $\begin{array}{l}-0.034^{* * *} \\
(0.002)\end{array}$ & $\begin{array}{l}0.237^{* * *} \\
(0.007)\end{array}$ & $\begin{array}{l}0.406^{* * *} \\
(0.007)\end{array}$ \\
\hline Birth order 4 & $\begin{array}{l}307.331^{* * *} \\
(5.573)\end{array}$ & $\begin{array}{l}-0.045^{* * *} \\
(0.002)\end{array}$ & $\begin{array}{l}0.038^{* * *} \\
(0.002)\end{array}$ & $\begin{array}{c}-0.037^{* * *} \\
(0.003)\end{array}$ & $\begin{array}{l}0.325^{* * *} \\
(0.012)\end{array}$ & $\begin{array}{l}0.482^{* * *} \\
(0.012)\end{array}$ \\
\hline Observations & $1,085,598$ & $1,085,598$ & $1,085,598$ & $1,085,598$ & $1,085,598$ & $1,085,598$ \\
\hline Mean & 3530.69 & 0.03 & 0.03 & 0.04 & 9.86 & 0.00 \\
\hline F-test of joint significance & 5513.05 & 619.93 & 402.39 & 476.57 & 522.50 & 2533.68 \\
\hline
\end{tabular}

Notes: The table shows the effect of birth order on health at birth. Each column presents a separate regression. The sample includes families with two to four children. The omitted category is birth order one. All regressions include family fixed effects, interactions between year of conception and month of conception dummies and a dummy for gender of the child. Standard errors, clustered at the family level, are in parentheses. The p-value for the joint test for significance (equality of birth order coefficients) is below 0.001 in all columns. The health index (mean of zero and standard deviation of one) is an equally weighted summary index of the variables in columns $(1)$ to $(5) .{ }^{*} p<0.10,{ }^{* *} p<0.05$, ${ }^{* * *} p<0.01$ 
Table 3

Effect of Birth Order on Child Health at Birth by Family Size

\begin{tabular}{|c|c|c|c|c|c|c|}
\hline & $\begin{array}{l}\text { Birth weight } \\
\quad \text { (grams) }\end{array}$ & $\begin{array}{l}\text { Low birth weight } \\
(<2500 \text { grams })\end{array}$ & $\begin{array}{l}\text { High birth weight } \\
\text { (> }>4500 \text { grams })\end{array}$ & $\begin{array}{l}\text { Prematurity } \\
(<37 \text { weeks })\end{array}$ & Apgar score & Health index \\
\hline \multicolumn{7}{|l|}{ (a) Two-child family } \\
\hline & $(1)$ & $(2)$ & $(3)$ & $(4)$ & $(5)$ & $(6)$ \\
\hline Birth order 2 & $\begin{array}{l}185.174^{* * *} \\
(2.651)\end{array}$ & $\begin{array}{l}-0.024^{* * *} \\
(0.001)\end{array}$ & $\begin{array}{l}0.021^{* * *} \\
(0.001)\end{array}$ & $\begin{array}{l}-0.024^{* * *} \\
(0.001)\end{array}$ & $\begin{array}{l}0.088^{* * *} \\
(0.005)\end{array}$ & $\begin{array}{l}0.214^{* * *} \\
(0.006)\end{array}$ \\
\hline Observations & 481,256 & 481,256 & 481,256 & 481,256 & 481,256 & 481,256 \\
\hline Mean & 3504.24 & 0.03 & 0.03 & 0.04 & 9.86 & -0.02 \\
\hline \multicolumn{7}{|l|}{ (b) Three-child family } \\
\hline & (1) & $(2)$ & $(3)$ & $(4)$ & $(5)$ & (6) \\
\hline Birth order 2 & $\begin{array}{c}188.432^{* * *} \\
(2.894)\end{array}$ & $\begin{array}{l}-0.027^{* * *} \\
(0.001)\end{array}$ & $\begin{array}{l}0.020^{* * *} \\
(0.001)\end{array}$ & $\begin{array}{l}-0.027^{* * *} \\
(0.001)\end{array}$ & $\begin{array}{l}0.174^{* * *} \\
(0.007)\end{array}$ & $\begin{array}{l}0.271^{* * *} \\
(0.007)\end{array}$ \\
\hline Birth order 3 & $\begin{array}{c}273.673^{* * *} \\
(5.522)\end{array}$ & $\begin{array}{c}-0.042^{* * *} \\
(0.002)\end{array}$ & $\begin{array}{l}0.033^{* * *} \\
(0.002)\end{array}$ & $\begin{array}{c}-0.039^{* * *} \\
(0.002)\end{array}$ & $\begin{array}{l}0.345^{* * *} \\
(0.013)\end{array}$ & $\begin{array}{l}0.434^{* * *} \\
(0.014)\end{array}$ \\
\hline Observations & 244,624 & 244,624 & 244,624 & 244,624 & 244,624 & 244,624 \\
\hline Mean & 3564.40 & 0.03 & 0.04 & 0.04 & 9.84 & 0.02 \\
\hline F-test of joint significance & 2138.05 & 268.80 & 160.48 & 212.84 & 363.86 & 681.75 \\
\hline \multicolumn{7}{|l|}{ (c) Four-child family } \\
\hline & $(1)$ & $(2)$ & $(3)$ & $(4)$ & $(5)$ & $(6)$ \\
\hline Birth order 2 & $\begin{array}{l}159.775^{* * *} \\
(5.865)\end{array}$ & $\begin{array}{l}-0.025^{* * *} \\
(0.003)\end{array}$ & $\begin{array}{l}0.016^{* * *} \\
(0.002)\end{array}$ & $\begin{array}{l}-0.021^{* * *} \\
(0.003)\end{array}$ & $\begin{array}{l}0.161^{* * *} \\
(0.016)\end{array}$ & $\begin{array}{l}0.240^{* * *} \\
(0.016)\end{array}$ \\
\hline Birth order 3 & $\begin{array}{c}252.462^{* * *} \\
(9.283)\end{array}$ & $\begin{array}{c}-0.045^{* * *} \\
(0.004)\end{array}$ & $\begin{array}{l}0.030^{* * *} \\
(0.004)\end{array}$ & $\begin{array}{c}-0.040^{* * *} \\
(0.004)\end{array}$ & $\begin{array}{l}0.337^{* * *} \\
(0.023)\end{array}$ & $\begin{array}{l}0.430^{* * *} \\
(0.024)\end{array}$ \\
\hline Birth order 4 & $\begin{array}{l}301.579^{* * *} \\
(13.741)\end{array}$ & $\begin{array}{c}-0.057^{* * *} \\
(0.006)\end{array}$ & $\begin{array}{l}0.038^{* * *} \\
(0.005)\end{array}$ & $\begin{array}{c}-0.046^{* * *} \\
(0.006)\end{array}$ & $\begin{array}{l}0.526^{* * *} \\
(0.034)\end{array}$ & $\begin{array}{l}0.573^{* * *} \\
(0.036)\end{array}$ \\
\hline Observations & 60,630 & 60,630 & 60,630 & 60,630 & 60,630 & 60,630 \\
\hline
\end{tabular}


Table 3 continued

\begin{tabular}{|c|c|c|c|c|c|c|}
\hline Mean & 3546.88 & 0.03 & 0.04 & 0.04 & 9.82 & -0.02 \\
\hline F-test of joint significance & 298.83 & 46.31 & 26.44 & 31.65 & 82.66 & 110.62 \\
\hline
\end{tabular}

Notes: The table shows the effect of birth order on health at birth. Each column presents a separate regression. Panel (a) includes families with two children, panel (b) includes families with three children, and panel (c) includes families with four children. The omitted category in all panels is birth order one. We exclude families where the mother is younger than 38 in December 2010. All regressions include family fixed effects, interactions between year of conception and month of conception dummies, and a dummy for gender of the child. Standard errors, clustered at the family level, are in parentheses. The p-value for the joint test for significance (equality of birth order coefficients) is below 0.001 in all columns in panel (b) and (c). The health index (mean of zero and standard deviation of one) is an equally weighted summary index of the variables in columns (1) to (5). ${ }^{*}$ $p<0.10,{ }^{* *} p<0.05,{ }^{* * *} p<0.01$ 
Table 4

Effect of Birth Order on Smoking During Pregnancy

\begin{tabular}{|c|c|c|c|c|c|c|}
\hline & \multicolumn{2}{|c|}{ Smoking anytime during pregnancy } & \multicolumn{4}{|c|}{ Smoking at the end of pregnancy } \\
\hline & (since 1991) & (since 1997) & \multicolumn{3}{|c|}{ daily number of cigarettes smoked } & \multirow[b]{2}{*}{ yes } \\
\hline & yes & yes & $\leq 5$ & $6-10$ & $\geq 11$ & \\
\hline & $(1)$ & $(2)$ & $(3)$ & $(4)$ & $(5)$ & $(6)$ \\
\hline Birth order 2 & $\begin{array}{c}-0.027^{* * *} \\
(0.001)\end{array}$ & $\begin{array}{c}-0.029^{* * *} \\
(0.001)\end{array}$ & $\begin{array}{c}-0.006^{* * *} \\
(0.001)\end{array}$ & $\begin{array}{c}-0.001 \\
(0.001)\end{array}$ & $\begin{array}{c}-0.003^{* * *} \\
(0.001)\end{array}$ & $\begin{array}{c}-0.010^{* * *} \\
(0.001)\end{array}$ \\
\hline Birth order 3 & $\begin{array}{c}-0.033^{* * *} \\
(0.002)\end{array}$ & $\begin{array}{c}-0.035^{* * *} \\
(0.003)\end{array}$ & $\begin{array}{c}-0.005^{* *} \\
(0.002)\end{array}$ & $\begin{array}{c}0.000 \\
(0.002)\end{array}$ & $\begin{array}{c}-0.005^{* * *} \\
(0.002)\end{array}$ & $\begin{array}{c}-0.011^{* * *} \\
(0.003)\end{array}$ \\
\hline Birth order 4 & $\begin{array}{c}-0.034^{* * *} \\
(0.004)\end{array}$ & $\begin{array}{c}-0.038^{* * *} \\
(0.004)\end{array}$ & $\begin{array}{r}-0.004 \\
(0.004)\end{array}$ & $\begin{array}{c}0.001 \\
(0.004)\end{array}$ & $\begin{array}{r}-0.005^{*} \\
(0.003)\end{array}$ & $\begin{array}{r}-0.008^{*} \\
(0.004)\end{array}$ \\
\hline Observations & 726,743 & 476,865 & 476,865 & 476,865 & 476,865 & 476,865 \\
\hline Mean & 0.17 & 0.13 & 0.04 & 0.04 & 0.03 & 0.11 \\
\hline F-test of joint significance & 282.43 & 258.32 & 19.75 & 1.69 & 5.54 & 50.47 \\
\hline
\end{tabular}

Notes: The table shows the effect of birth order on smoking during pregnancy. Each column represents a separate regression. The sample includes families with two to four children. The omitted category is birth order one. All regressions include family fixed effects, interactions between year of conception and month of conception dummies, and a dummy for gender of the child. Standard errors, clustered at the family level, are in parentheses. Except for column (4), the p-value for the joint test for significance (equality of birth order coefficients) is below $0.001 .{ }^{*} p<0.10,{ }^{* *} p<0.05,{ }^{* * *} p<0.01$ 
Table 5

Effect of Birth Order on Prenatal Checkups and Maternal Health

\begin{tabular}{|c|c|c|c|c|c|}
\hline & \multicolumn{2}{|c|}{ \# Prenatal checkups } & \multicolumn{3}{|c|}{ Maternal health } \\
\hline & midwife & $\begin{array}{c}\text { special } \\
\text { practitioner }\end{array}$ & $\begin{array}{c}\text { gestational } \\
\text { diabetes }\end{array}$ & $\begin{array}{l}\text { gestational } \\
\text { hypertension }\end{array}$ & preeclampsia \\
\hline & (1) & $(2)$ & $(3)$ & $(4)$ & $(5)$ \\
\hline Birth order 2 & $\begin{array}{c}-0.119^{* * *} \\
(0.006)\end{array}$ & $\begin{array}{c}-0.186^{* * *} \\
(0.006)\end{array}$ & $\begin{array}{c}-0.006^{* * *} \\
(0.000)\end{array}$ & $\begin{array}{c}-0.006^{* * *} \\
(0.000)\end{array}$ & $\begin{array}{c}-0.029^{* * *} \\
(0.001)\end{array}$ \\
\hline Birth order 3 & $\begin{array}{c}-0.230^{* * *} \\
(0.013)\end{array}$ & $\begin{array}{c}-0.286^{* * *} \\
(0.012)\end{array}$ & $\begin{array}{c}-0.013^{* * *} \\
(0.001)\end{array}$ & $\begin{array}{c}-0.009^{* * *} \\
(0.001)\end{array}$ & $\begin{array}{c}-0.034^{* * *} \\
(0.001)\end{array}$ \\
\hline Birth order 4 & $\begin{array}{c}-0.275^{* * *} \\
(0.022)\end{array}$ & $\begin{array}{c}-0.416^{* * *} \\
(0.020)\end{array}$ & $\begin{array}{c}-0.011^{* * *} \\
(0.002)\end{array}$ & $\begin{array}{c}-0.010^{* * *} \\
(0.001)\end{array}$ & $\begin{array}{c}-0.037^{* * *} \\
(0.002)\end{array}$ \\
\hline Observations & $1,031,509$ & $1,077,891$ & $1,105,306$ & $1,105,306$ & $1,105,306$ \\
\hline Mean & 4.12 & 4.85 & 0.01 & 0.01 & 0.03 \\
\hline F-test of joint significance & 129.59 & 374.76 & 86.60 & 143.19 & $1,180.91$ \\
\hline
\end{tabular}

Notes: The table shows the effect of birth order on prenatal checkups and maternal health. Each column represents a separate regression. The sample includes families with two to four children. The omitted category is birth order one. All regressions include family fixed effects, interactions between year of conception and month of conception dummies, and a dummy for gender of the child. Standard errors, clustered at the family level, are in parentheses. The p-value for the joint test for significance (equality of birth order coefficients) is below 0.001 in all columns. ${ }^{*} p<0.10,{ }^{* *} p<0.05,{ }^{* * *} p<0.01$ 
Table 6

Characteristics of Hospitalization Sample

\begin{tabular}{|c|c|c|c|}
\hline Variable & Mean & S.D. & $\mathrm{N}$ \\
\hline \multicolumn{4}{|c|}{ (a) Hospitalization for general health conditions } \\
\hline All age groups & 0.082 & 0.274 & $10,729,543$ \\
\hline Age 1 & 0.150 & 0.357 & 678,788 \\
\hline Age 2 & 0.097 & 0.296 & 679,606 \\
\hline Age 3 & 0.084 & 0.278 & 679,181 \\
\hline Age 4 & 0.077 & 0.266 & 676,339 \\
\hline Age 5 & 0.070 & 0.255 & 671,980 \\
\hline Age 6 & 0.064 & 0.244 & 664,364 \\
\hline Age 7 & 0.060 & 0.237 & 654,720 \\
\hline Age 8 & 0.058 & 0.233 & 644,124 \\
\hline Age 9 & 0.056 & 0.230 & 631,493 \\
\hline Age 10 & 0.056 & 0.229 & 617,530 \\
\hline Age 11 & 0.057 & 0.232 & 599,573 \\
\hline Age 12 & 0.059 & 0.236 & 578,363 \\
\hline Age 13 & 0.064 & 0.245 & 554,492 \\
\hline Age 14 & 0.075 & 0.263 & 509,296 \\
\hline Age 15 & 0.086 & 0.280 & 463,649 \\
\hline Age 16 & 0.091 & 0.288 & 419,358 \\
\hline \multicolumn{4}{|c|}{ (b) Hospitalization for injuries } \\
\hline All age groups & 0.124 & 0.329 & $10,729,543$ \\
\hline Age 1 & 0.127 & 0.333 & 678,788 \\
\hline Age 2 & 0.120 & 0.325 & 679,606 \\
\hline Age 3 & 0.115 & 0.319 & 679,181 \\
\hline Age 4 & 0.102 & 0.302 & 676,339 \\
\hline Age 5 & 0.092 & 0.289 & 671,980 \\
\hline Age 6 & 0.089 & 0.285 & 664,364 \\
\hline Age 7 & 0.089 & 0.285 & 654,720 \\
\hline Age 8 & 0.096 & 0.294 & 644,124 \\
\hline Age 9 & 0.104 & 0.305 & 631,493 \\
\hline Age 10 & 0.113 & 0.317 & 617,530 \\
\hline Age 11 & 0.121 & 0.327 & 599,573 \\
\hline Age 12 & 0.124 & 0.330 & 578,363 \\
\hline Age 13 & 0.125 & 0.331 & 554,492 \\
\hline Age 14 & 0.124 & 0.329 & 509,296 \\
\hline Age 15 & 0.121 & 0.327 & 463,649 \\
\hline Age 16 & 0.123 & 0.328 & 419,358 \\
\hline
\end{tabular}

Notes: The table shows summary statistics for the probability of a hospitalization at every age, from age 1 through age 16. Panel (a) presents summary statistics for the probability of a hospitalization for ICD-10 diagnosis codes chapter I-XIV [A-N]. Panel (b) presents summary statistics for the probability of a hospitalization for ICD-10 diagnosis codes chapter XIX [S, T0-14]. Included in the sample are all observations from families with at least two children with non-missing hospitalization records at a given age of the children. 


\section{A Appendix (for online publication only)}

This is the supplementary material for the article "Birth Order and Health of Newborns: What Can We Learn from Danish Registry Data?" by Anne Ardila Brenøe and Ramona Molitor.

\section{A.1 The Nature Hypothesis}

The general understanding in the medical literature is that physiological changes during the first pregnancy, necessary for fetal development, do not fully return to their baseline value (before the first pregnancy). Higher order pregnancies profit from this incomplete reversal. These physiological changes encompass the uterine blood supply (Hafner et al., 2000; Hollis et al., 2003; Khong et al., 2003; Prefumo et al., 2004) and an enlargement of the uterus (Woessner and Brewer, 1963; Sørnes and Bakke, 1989), both of which affect nutrient supply to the fetus (Gluckman and Hanson, 2004). It has also been suggested that maternal sensitization to paternal antigens that occur at the first pregnancy affect birth weight of later-born children (Warburton and Naylor, 1971; Chakraborty et al., 1975).

Animal studies perpetuate the findings from the medical literature. A positive effect of birth order on health at birth appears for cattle (Johanson and Berger, 2003) as well as sheep (Gardner et al., 2007). Animal studies occur in a controlled environment, , for example, with respect to nutrition, and therefore alleviate concerns about endogenous behavioral differences of the mother. 


\section{A.2 Supplementary Figures and Tables}

Figure A1

The Effect of Birth Order on Health at Birth by Maternal Age at First Birth

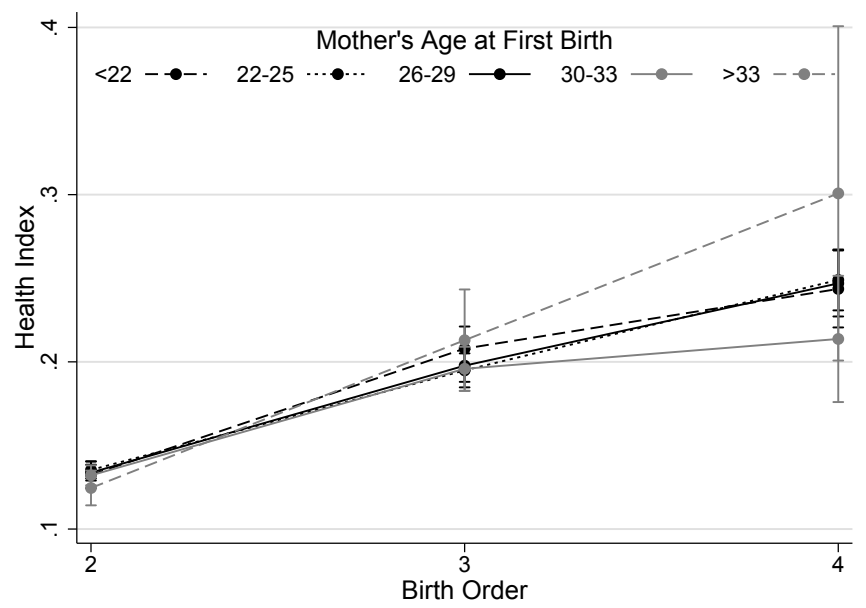

Notes: The figure plots the coefficients of the interaction term between birth order and maternal age at first birth in the family fixed effects model (model 1 where the three birth order dummies are interacted with five dummies for maternal age at first birth). The dependent variable is the health index (mean of zero and standard deviation of one) that is an equally weighted summary index of the following variables: birth weight, low birth weight, high birth weight, prematurity, and Apgar score. Age at first birth is divided into (1) < 22 years, (2) 22-25 years, (3) 26-29 years, (4) 30-33 years, (5) >33 years. The regression includes family fixed effects, interactions between year of conception and month of conception dummies, and a dummy for gender of the child. The whiskers indicate the 95 percent confidence interval. 


\section{Figure A2}

The Effect of Birth Order on Health at Birth by Mother's Highest Education

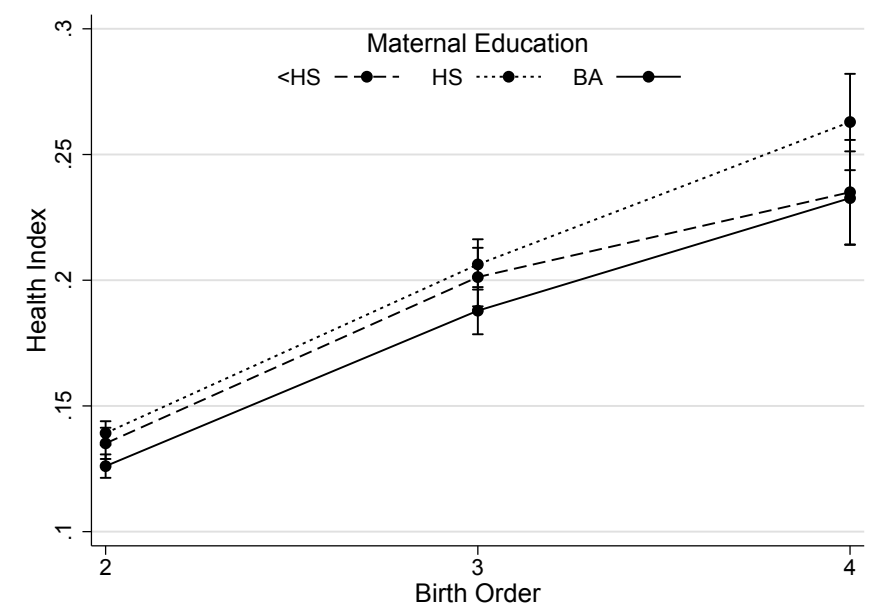

Notes: The figure plots the coefficients of the interaction term between birth order and education of the mother in the family fixed effects model (model 1 where the three birth order dummies are interacted with three dummies for mother's highest education). The dependent variable is the health index (mean of zero and standard deviation of one) that is an equally weighted summary index of the following variables: birth weight, low birth weight, high birth weight, prematurity, and Apgar score. Education is divided into (1) < HS: no high school/education ( $<12$ years), (2) HS: high school and potentially some vocational training or two years of college, and (3) BA: Bachelor degree or more. The regression includes family fixed effects, interactions between year of conception and month of conception dummies, and a dummy for gender of the child. The whiskers indicate the 95 percent confidence interval. 


\section{Figure A3}

The Effect of Birth Order on Health at Birth by Gender of the Child

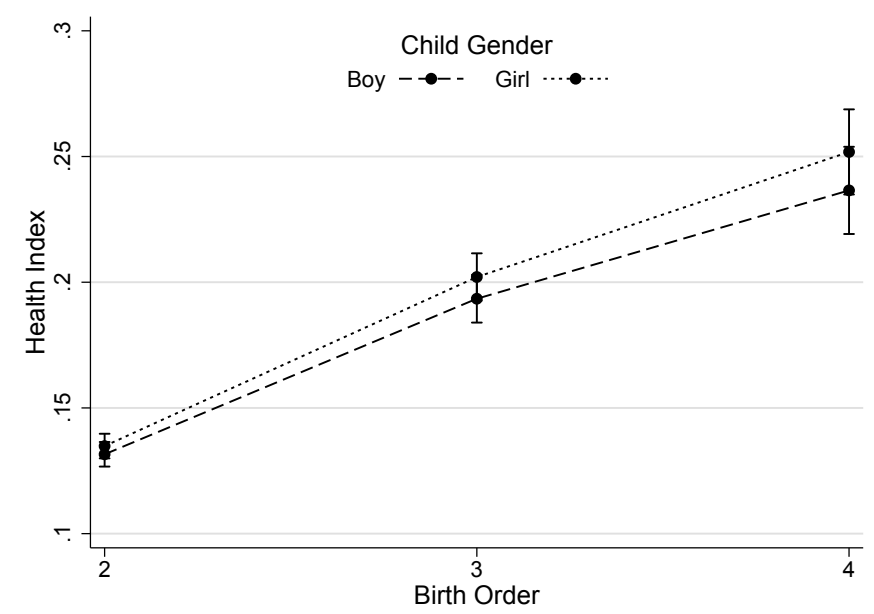

Notes: The figure plots the coefficients of the interaction term between birth order and gender of the child (model 1 where the three birth order dummies are interacted with a dummy for boy and a dummy for girl). The dependent variable is the health index (mean of zero and standard deviation of one) that is an equally weighted summary index of the following variables: birth weight, low birth weight, high birth weight, prematurity, and Apgar score. The regression includes family fixed effects, interactions between year of conception and month of conception dummies, and a dummy for gender of the child. The whiskers indicate the 95 percent confidence interval. 
Table A1

Effect of Birth Order on Ninth Grade GPA

\begin{tabular}{lcccc}
\hline & Pooled & 2-Child Family & 3-Child Family & 4-Child Family \\
\hline Birth order 2 & $(1)$ & $(2)$ & $(3)$ & $(4)$ \\
& $-0.163^{* * *}$ & $-0.165^{* * *}$ & $-0.166^{* * *}$ & $-0.139^{* * *}$ \\
Birth order 3 & $(0.007)$ & $(0.010)$ & $(0.010)$ & $(0.019)$ \\
& $-0.238^{* * *}$ & & $-0.271^{* * *}$ & $-0.269^{* * *}$ \\
Birth order 4 & $(0.014)$ & & $(0.021)$ & $(0.036)$ \\
& $-0.294^{* * *}$ & & & $-0.368^{* * *}$ \\
\hline Observations & $(0.024)$ & & & $(0.055)$ \\
Mean & 242,115 & 134,626 & 84,051 & 22,313 \\
\hline
\end{tabular}

Notes: The table shows the effect of birth order on ninth grade GPA. Each column presents a separate regression. The GPA is based on grades from national exams in Danish, Math, and English, and are given for oral and written presentation as well as reading comprehension. The GPA is standardized by year of graduation to a mean of zero and standard deviation of one at the population level. Column (1) includes all families with two to four children, column (2) includes only families with two children, column (3) includes only families with three children, and column (4) includes only families with four children. The omitted category is birth order one. All regressions include dummies for year by month of conception, and gender of the child. Standard errors, clustered at the family level, are in parentheses. ${ }^{*} p<0.10,{ }^{* *} p<0.05,{ }^{* * *} p<0.01$ 
Table A2

Effect of Birth Order on Child Health at Birth - Additional Measures

\begin{tabular}{|c|c|c|c|c|c|c|c|c|}
\hline & $\begin{array}{l}\log \\
\text { birth weight }\end{array}$ & $\begin{array}{c}\log \\
\text { birth length }\end{array}$ & BWZ & SGA & LGA & $\begin{array}{c}\text { Head } \\
\text { Circumference }\end{array}$ & $\begin{array}{l}\text { Perinatal } \\
\text { Conditions }\end{array}$ & $\begin{array}{l}\text { Perinatal } \\
\text { Death }\end{array}$ \\
\hline & $(1)$ & $(2)$ & $(3)$ & (4) & $(5)$ & $(6)$ & $(7)$ & $(8)$ \\
\hline Birth order 2 & $\begin{array}{l}0.058^{* * *} \\
(0.001)\end{array}$ & $\begin{array}{l}0.010^{* * *} \\
(0.000)\end{array}$ & $\begin{array}{l}0.401^{* * *} \\
(0.003)\end{array}$ & $\begin{array}{c}-0.030^{* * *} \\
(0.001)\end{array}$ & $\begin{array}{l}0.023^{* * *} \\
(0.001)\end{array}$ & $\begin{array}{l}0.350^{* * *} \\
(0.009)\end{array}$ & $\begin{array}{c}-0.078^{* * *} \\
(0.002)\end{array}$ & $\begin{array}{c}-0.021^{* * *} \\
(0.000)\end{array}$ \\
\hline Birth order 3 & $\begin{array}{l}0.083^{* * *} \\
(0.001)\end{array}$ & $\begin{array}{l}0.015^{* * *} \\
(0.000)\end{array}$ & $\begin{array}{l}0.560^{* * *} \\
(0.006)\end{array}$ & $\begin{array}{c}-0.041^{* * *} \\
(0.001)\end{array}$ & $\begin{array}{l}0.037^{\text {*** }} \\
(0.001)\end{array}$ & $\begin{array}{l}0.508^{* * *} \\
(0.018)\end{array}$ & $\begin{array}{c}-0.098^{* * *} \\
(0.004)\end{array}$ & $\begin{array}{c}-0.053^{* * *} \\
(0.001)\end{array}$ \\
\hline Birth order 4 & $\begin{array}{l}0.098^{* * *} \\
(0.002)\end{array}$ & $\begin{array}{l}0.018^{* * *} \\
(0.001)\end{array}$ & $\begin{array}{l}0.682^{\text {*** }} \\
(0.010)\end{array}$ & $\begin{array}{c}-0.052^{* * *} \\
(0.002)\end{array}$ & $\begin{array}{l}0.045^{* * *} \\
(0.002)\end{array}$ & $\begin{array}{l}0.607^{* * *} \\
(0.030)\end{array}$ & $\begin{array}{c}-0.102^{* * *} \\
(0.006)\end{array}$ & $\begin{array}{c}-0.084^{* * *} \\
(0.002)\end{array}$ \\
\hline Observations & $1,085,598$ & $1,069,604$ & $1,085,598$ & $1,085,598$ & $1,085,598$ & 472,566 & 622,114 & $1,105,291$ \\
\hline Mean & 8.16 & 3.95 & -0.08 & 0.03 & 0.03 & 35.17 & 0.14 & 0.01 \\
\hline F-test of joint significance & 4483.53 & 1621.29 & 6903.77 & 868.22 & 503.21 & 642.38 & 889.47 & 1161.03 \\
\hline
\end{tabular}

Notes: The table shows the effect of birth order on health at birth for additional measures of health at birth. Each column presents a separate regression. BZW is birth weight z-score and relates the birth weight of a child at a given gestational age at birth to what would be expected for a healthy child at the same gestational age. SGA is small for gestation age and is a dummy taking the value one if the birth weight z-score falls below -2 standard deviations and zero otherwise. LGA is large for gestational age and is a dummy taking the value one if the birth weight z-score exceeds +2 standard deviations and zero otherwise. Head circumference is in cm and reported since 1997. Perinatal condition indicates the diagnosis of a condition originating in the perinatal period, includes ICD-10 codes P00 to P96, and is measured within the first year of birth (we exclude the codes P05 to P08 since these indicate birth weight and gestational age and we look at these outcomes already separately). Perinatal death is defined as fetal deaths occurring with a stated or presumed gestation of 28 weeks or more or deaths occurring within the first seven days of life. The sample includes families with two to four children. The omitted category is birth order one. All regressions include family fixed effects, interactions between year of conception and month of conception dummies, and a dummy for gender of the child. Standard errors, clustered at the family level, are in parentheses. The p-value for the joint test for significance (equality of birth order coefficients) is below 0.001 in all columns. The health index is an equally weighted summary index of the variables in column (1) to (5). ${ }^{*} p<0.10,{ }^{* *} p<0.05,{ }^{* * *} p<0.01$ 
Table A3

Effect of Birth Order on Health Throughout Childhood

\begin{tabular}{|c|c|c|c|c|}
\hline & \multicolumn{4}{|c|}{ Probability of a hospitalization for } \\
\hline & \multicolumn{2}{|c|}{ any health conditions } & \multicolumn{2}{|c|}{ injuries } \\
\hline & $\begin{array}{l}\text { point estimate } \\
\text { (standard error) }\end{array}$ & $\begin{array}{c}\mathrm{p} \text {-value } \\
\text { difference }\end{array}$ & $\begin{array}{c}\text { point estimate } \\
\text { (standard error) }\end{array}$ & $\begin{array}{l}\mathrm{p} \text {-value } \\
\text { difference }\end{array}$ \\
\hline (percentage points) & (1) & $(2)$ & $(3)$ & $(4)$ \\
\hline Birth order $2 \times$ age 1 & $\begin{array}{c}-0.391^{* *} \\
(0.172)\end{array}$ & & $\begin{array}{l}2.566^{* * *} \\
(0.155)\end{array}$ & \\
\hline Birth order $2 \times$ age 2 & $\begin{array}{l}-0.632^{* * *} \\
(0.147)\end{array}$ & 0.29 & $\begin{array}{l}2.343^{* * *} \\
(0.157)\end{array}$ & 0.31 \\
\hline Birth order $2 \times$ age 3 & $\begin{array}{l}-0.772^{* * *} \\
(0.139)\end{array}$ & 0.49 & $\begin{array}{l}2.101^{* * *} \\
(0.157)\end{array}$ & 0.28 \\
\hline Birth order $2 \times$ age 4 & $\begin{array}{l}-0.627^{* * *} \\
(0.133)\end{array}$ & 0.45 & $\begin{array}{l}1.873^{* * *} \\
(0.151)\end{array}$ & 0.30 \\
\hline Birth order $2 \times$ age 5 & $\begin{array}{r}-0.241^{*} \\
(0.128)\end{array}$ & 0.04 & $\begin{array}{l}1.480^{* * *} \\
(0.148)\end{array}$ & 0.06 \\
\hline Birth order $2 \times$ age 6 & $\begin{array}{l}-0.366^{* * *} \\
(0.123)\end{array}$ & 0.48 & $\begin{array}{l}1.362^{* * *} \\
(0.147)\end{array}$ & 0.57 \\
\hline Birth order $2 \times$ age 7 & $\begin{array}{r}-0.085 \\
(0.119)\end{array}$ & 0.10 & $\begin{array}{l}0.782^{* * *} \\
(0.150)\end{array}$ & 0.01 \\
\hline Birth order $2 \times$ age 8 & $\begin{array}{r}-0.096 \\
(0.119)\end{array}$ & 0.95 & $\begin{array}{l}0.884^{* * *} \\
(0.156)\end{array}$ & 0.64 \\
\hline Birth order $2 \times$ age 9 & $\begin{array}{r}-0.008 \\
(0.119)\end{array}$ & 0.60 & $\begin{array}{l}1.113^{* * *} \\
(0.164)\end{array}$ & 0.31 \\
\hline Birth order $2 \times$ age 10 & $\begin{array}{c}0.084 \\
(0.118)\end{array}$ & 0.58 & $\begin{array}{l}0.701^{* * *} \\
(0.173)\end{array}$ & 0.08 \\
\hline Birth order $2 \times$ age 11 & $\begin{array}{c}0.144 \\
(0.123)\end{array}$ & 0.73 & $\begin{array}{l}0.917^{* * *} \\
(0.185)\end{array}$ & 0.40 \\
\hline Birth order $2 \times$ age 12 & $\begin{array}{c}0.008 \\
(0.127)\end{array}$ & 0.44 & $\begin{array}{l}0.734^{* * *} \\
(0.192)\end{array}$ & 0.49 \\
\hline Birth order $2 \times$ age 13 & $\begin{array}{l}0.352^{* * *} \\
(0.136)\end{array}$ & 0.06 & $\begin{array}{l}0.708^{* * *} \\
(0.198)\end{array}$ & 0.92 \\
\hline Birth order $2 \times$ age 14 & $\begin{array}{r}0.273^{*} \\
(0.153)\end{array}$ & 0.70 & $\begin{array}{l}1.008^{* * *} \\
(0.207)\end{array}$ & 0.29 \\
\hline Birth order $2 \times$ age 15 & $\begin{array}{c}0.147 \\
(0.173)\end{array}$ & 0.59 & $\begin{array}{l}1.531^{* * *} \\
(0.220)\end{array}$ & 0.08 \\
\hline Birth order $2 \times$ age 16 & $\begin{array}{c}0.464^{* *} \\
(0.187)\end{array}$ & 0.21 & $\begin{array}{l}1.797^{* * *} \\
(0.238)\end{array}$ & 0.41 \\
\hline Birth order $3 \times$ age 1 & $\begin{array}{c}-0.052 \\
(0.353)\end{array}$ & & $\begin{array}{l}3.666^{* * *} \\
(0.317)\end{array}$ & \\
\hline Birth order $3 \times$ age 2 & $\begin{array}{l}-1.124^{* * *} \\
(0.301)\end{array}$ & 0.02 & $\begin{array}{l}2.901^{* * *} \\
(0.321)\end{array}$ & 0.09 \\
\hline Birth order $3 \times$ age 3 & $\begin{array}{l}-1.400^{* * *} \\
(0.282)\end{array}$ & 0.50 & $\begin{array}{l}2.799^{* * *} \\
(0.320)\end{array}$ & 0.82 \\
\hline Birth order $3 \times$ age 4 & $\begin{array}{c}-1.134^{* * *} \\
(0.271)\end{array}$ & 0.50 & $\begin{array}{l}2.357^{* * *} \\
(0.307)\end{array}$ & 0.32 \\
\hline Birth order $3 \times$ age 5 & $\begin{array}{r}-0.465^{*} \\
(0.260)\end{array}$ & 0.07 & $\begin{array}{l}2.179^{* * *} \\
(0.302)\end{array}$ & 0.68 \\
\hline Birth order $3 \times$ age 6 & $\begin{array}{l}-0.692^{* * *} \\
(0.249)\end{array}$ & 0.53 & $\begin{array}{l}2.006^{* * *} \\
(0.301)\end{array}$ & 0.68 \\
\hline Birth order $3 \times$ age 7 & -0.346 & 0.32 & $0.862^{* * *}$ & 0.01 \\
\hline
\end{tabular}


Table A3 continued

\begin{tabular}{|c|c|c|c|c|}
\hline & $(0.243)$ & & $(0.307)$ & \\
\hline Birth order $3 \times$ age 8 & $\begin{array}{c}-0.244 \\
(0.242)\end{array}$ & 0.77 & $\begin{array}{l}1.079^{* * *} \\
(0.319)\end{array}$ & 0.62 \\
\hline Birth order $3 \times$ age 9 & $\begin{array}{r}-0.134 \\
(0.244)\end{array}$ & 0.75 & $\begin{array}{l}1.283^{* * *} \\
(0.336)\end{array}$ & 0.66 \\
\hline Birth order $3 \times$ age 10 & $\begin{array}{c}0.012 \\
(0.242)\end{array}$ & 0.67 & $\begin{array}{c}0.837^{* *} \\
(0.354)\end{array}$ & 0.36 \\
\hline Birth order $3 \times$ age 11 & $\begin{array}{r}-0.007 \\
(0.253)\end{array}$ & 0.96 & $\begin{array}{l}1.185^{* * *} \\
(0.378)\end{array}$ & 0.50 \\
\hline Birth order $3 \times$ age 12 & $\begin{array}{c}-0.079 \\
(0.261)\end{array}$ & 0.84 & $\begin{array}{l}1.034^{* * *} \\
(0.392)\end{array}$ & 0.78 \\
\hline Birth order $3 \times$ age 13 & $\begin{array}{l}0.765^{\text {*** }} \\
(0.280)\end{array}$ & 0.03 & $\begin{array}{l}1.485^{* * *} \\
(0.404)\end{array}$ & 0.42 \\
\hline Birth order $3 \times$ age 14 & $\begin{array}{r}0.524 * \\
(0.315)\end{array}$ & 0.57 & $\begin{array}{l}1.742^{* * *} \\
(0.424)\end{array}$ & 0.66 \\
\hline Birth order $3 \times$ age 15 & $\begin{array}{c}0.354 \\
(0.353)\end{array}$ & 0.72 & $\begin{array}{l}2.358^{* * *} \\
(0.449)\end{array}$ & 0.32 \\
\hline Birth order $3 \times$ age 16 & $\begin{array}{c}0.943^{* *} \\
(0.386)\end{array}$ & 0.26 & $\begin{array}{l}2.440^{* * *} \\
(0.489)\end{array}$ & 0.90 \\
\hline Birth order $4 \times$ age 1 & $\begin{array}{r}-0.184 \\
(0.581)\end{array}$ & & $\begin{array}{l}5.119^{* * *} \\
(0.524)\end{array}$ & \\
\hline Birth order $4 \times$ age 2 & $\begin{array}{c}-1.499^{* * *} \\
(0.496)\end{array}$ & 0.09 & $\begin{array}{l}4.173^{* * *} \\
(0.535)\end{array}$ & 0.21 \\
\hline Birth order $4 \times$ age 3 & $\begin{array}{l}-1.334^{* * *} \\
(0.467)\end{array}$ & 0.81 & $\begin{array}{l}3.535^{* * *} \\
(0.529)\end{array}$ & 0.40 \\
\hline Birth order $4 \times$ age 4 & $\begin{array}{c}-1.302^{* * *} \\
(0.445)\end{array}$ & 0.96 & $\begin{array}{l}3.156^{* * *} \\
(0.507)\end{array}$ & 0.60 \\
\hline Birth order $4 \times$ age 5 & $\begin{array}{c}-0.653 \\
(0.428)\end{array}$ & 0.29 & $\begin{array}{l}3.255^{* * *} \\
(0.502)\end{array}$ & 0.89 \\
\hline Birth order $4 \times$ age 6 & $\begin{array}{r}-0.718^{*} \\
(0.408)\end{array}$ & 0.91 & $\begin{array}{l}2.419^{* * *} \\
(0.498)\end{array}$ & 0.24 \\
\hline Birth order $4 \times$ age 7 & $\begin{array}{r}-0.437 \\
(0.400)\end{array}$ & 0.62 & $\begin{array}{r}0.904^{*} \\
(0.505)\end{array}$ & 0.03 \\
\hline Birth order $4 \times$ age 8 & $\begin{array}{r}-0.147 \\
(0.404)\end{array}$ & 0.61 & $\begin{array}{l}1.459^{* * *} \\
(0.528)\end{array}$ & 0.45 \\
\hline Birth order $4 \times$ age 9 & $\begin{array}{c}0.204 \\
(0.406)\end{array}$ & 0.54 & $\begin{array}{l}1.385^{* *} \\
(0.556)\end{array}$ & 0.92 \\
\hline Birth order $4 \times$ age 10 & $\begin{array}{c}-0.126 \\
(0.404)\end{array}$ & 0.57 & $\begin{array}{l}1.249^{* *} \\
(0.589)\end{array}$ & 0.87 \\
\hline Birth order $4 \times$ age 11 & $\begin{array}{c}-0.137 \\
(0.426)\end{array}$ & 0.98 & $\begin{array}{l}1.972^{* * *} \\
(0.641)\end{array}$ & 0.41 \\
\hline Birth order $4 \times$ age 12 & $\begin{array}{c}0.042 \\
(0.444)\end{array}$ & 0.77 & $\begin{array}{c}0.506 \\
(0.664)\end{array}$ & 0.11 \\
\hline Birth order $4 \times$ age 13 & $\begin{array}{l}1.373^{* * *} \\
(0.489)\end{array}$ & 0.04 & $\begin{array}{l}1.906^{* * *} \\
(0.696)\end{array}$ & 0.15 \\
\hline Birth order $4 \times$ age 14 & $\begin{array}{c}0.697 \\
(0.547)\end{array}$ & 0.36 & $\begin{array}{l}3.320^{* * *} \\
(0.737)\end{array}$ & 0.16 \\
\hline Birth order $4 \times$ age 15 & $\begin{array}{c}0.796 \\
(0.633)\end{array}$ & 0.91 & $\begin{array}{l}3.825^{* * *} \\
(0.781)\end{array}$ & 0.64 \\
\hline Birth order $4 \times$ age 16 & $\begin{array}{l}1.384^{* *} \\
(0.697)\end{array}$ & 0.53 & $\begin{array}{l}4.317^{* * *} \\
(0.860)\end{array}$ & 0.67 \\
\hline
\end{tabular}


Table A3 continued

\begin{tabular}{lcc}
\hline Observations & $1,072,9534$ & $1,072,9534$ \\
Mean & 8.20 & 12.35
\end{tabular}

Notes: The table presents the effect of birth order on health throughout childhood. Column (1) presents the results for health conditions (probability of a hospitalization at each age for ICD-10 diagnosis codes chapter I-XIV [A-N]). Column (3) presents the results for injuries (probability of a hospitalization at each age, ICD-10 diagnosis codes XIX [S, T0-14]). We scale the results to percentage points $(\times 100)$. Column $(2)$ and $(4)$ depict the p-values of Wald tests that test the difference between the point estimate in the respective row and the point estimate from the previous age. The sample includes families with two to four children. The omitted category is birth order one. All regressions include interactions of all age dummies with family indicators, year by month of conception dummies, and a dummy for gender of the child. ${ }^{*} p<0.10,{ }^{* *} p<0.05,{ }^{* * *} p<0.01$ 


\section{Compliance with Ethical Standards}

The authors declare that they have no conflict of interest. 